\title{
CONTINUIDADES E HIATOS OCUPACIONALES DURANTE EL HOLOCENO MEDIO EN EL BORDE ORIENTAL DE LA PUNA SALADA, ANTOFAGASTA DE LA SIERRA, ARGENTINA
}

\author{
CONTINUITY AND HIATUSES IN MIDDLE HOLOCENE OCCUPATIONS OF \\ THE EASTERN RIM OF THE SALT PUNA, ANTOFAGASTA DE LA SIERRA, \\ ARGENTINA
}

\author{
Elizabeth Pintar ${ }^{1}$
}

\begin{abstract}
Este trabajo se centra en las ocupaciones en Cueva Salamanca 1 (Antofagasta de la Sierra, Puna salada argentina) durante el Holoceno Medio, un período de aridez generalizada en toda la Puna. Esta cueva fue un espacio óptimo donde grupos cazadores-recolectores realizaron actividades de subsistencia (caza y recolección) además de actividades de producción de tecnología y tecnofacturas. Se discute el efecto que las condiciones de aridez tuvieron sobre las estrategias de movilidad y asentamiento ca. 9.000-7.000 cal. a.p. (8.000-6.000 a.p.). Se comparan secuencias de ocupación e hiatos con otros sitios arqueológicos cercanos durante el inicio del Holoceno Medio en el marco de un incremento en las condiciones áridas para proponer la existencia de múltiples oasis fluviales a lo largo de ríos cuyas vertientes se originan en el borde oriental de la Puna Salada. Los hiatos ocupacionales posteriores a ca. 7.900 cal. a.p. (7.200 a.p.) sugieren condiciones de aún mayor aridez y una reorganización de los sistemas de movilidad y asentamiento.

Palabras claves: Puna salada argentina, Holoceno Medio, cazadores-recolectores, movilidad, obsidiana, oasis fluviales.
\end{abstract}

This paper focuses on the occupations in Salamanca Cave (Antofagasta de la Sierra, Argentine Salt Puna) during the Middle Holocene, a period of generalized aridity in the Puna. This cave was an optimal place where groups of hunter-gatherers carried out subsistence activities (hunting and gathering), as well as the production of technology and tools. The effect that the arid conditions had on mobility and settlement strategies ca. 9,000-7,000 cal. BP (8,000-6,000 BP) is discussed. The sequence of occupations and gaps is compared with that of neighboring sites during the early Middle Holocene within the framework of an increase in arid conditions in order to propose the existence of multiple fluvial oases along rivers whose headwaters originate in the eastern border of the Salt Puna. The occupation gaps following ca. 7,900 BP (7,200 BP) suggest increased arid conditions and the reorganization of mobility and settlement systems.

Key words: Argentine Salt Puna, Middle Holocene, hunter-gatherers, mobility, obsidian, fluvial oases.

Este estudio se enfoca en las sociedades prehistóricas que habitaron un gran desierto de altura, conocido como la Puna Salada, un ambiente hostil y susceptible a varios cambios climáticos y ambientales que sucedieron durante el Holoceno. Aquí se tratan las sociedades cazadoras-recolectoras que habitaron Cueva Salamanca 1 en la cuenca de la Laguna Antofagasta (Antofagasta de la Sierra, Provincia de Catamarca) en el noroeste Argentino durante el Holoceno Medio, que fue el momento más árido registrado en los últimos 10.000 años.

Este fue, sin duda, un período crítico para aquellos grupos de cazadores-recolectores cuyos modos de vida siempre estuvieron sujetos a los recursos que un ambiente desértico podía ofrecer. Paralelamente a esta aridez se ha documentado el abandono de ciertos sitios que habían sido habitados durante el Holoceno Temprano, tanto en Puna Norte argentina como en la Puna chilena (Núñez y Santoro 1988; Santoro y Núñez 1987; Yacobaccio y Morales 2005). Sin embargo, en la Puna Salada argentina no se registra tal abandono sino más bien lo contrario, una continuidad ocupacional a lo largo del Holoceno. Este es el caso en el sitio Cueva Salamanca 1 ocupado ca. 9.000-3.600 cal. a.p. (8.100-3.500 a.p.) (Figura 1).

Cueva Salamanca 1 se encuentra en el sector medio del río Las Pitas, a $8 \mathrm{~km}$ de distancia de Quebrada Seca 3, un sitio con una secuencia de ocupaciones entre ca. 11.200-2.500 cal. a.p. (9.800 y 2.500 a.p.; Aschero 1988; Pintar 1996). Las excavaciones en Cueva Salamanca 1 (Pintar 2004,

$1 \quad$ Social and Behavioral Sciences Department, Austin Community College. 11928 Stonehollow Drive, Austin, TX 78758, USA. lpintar@austincc.edu 


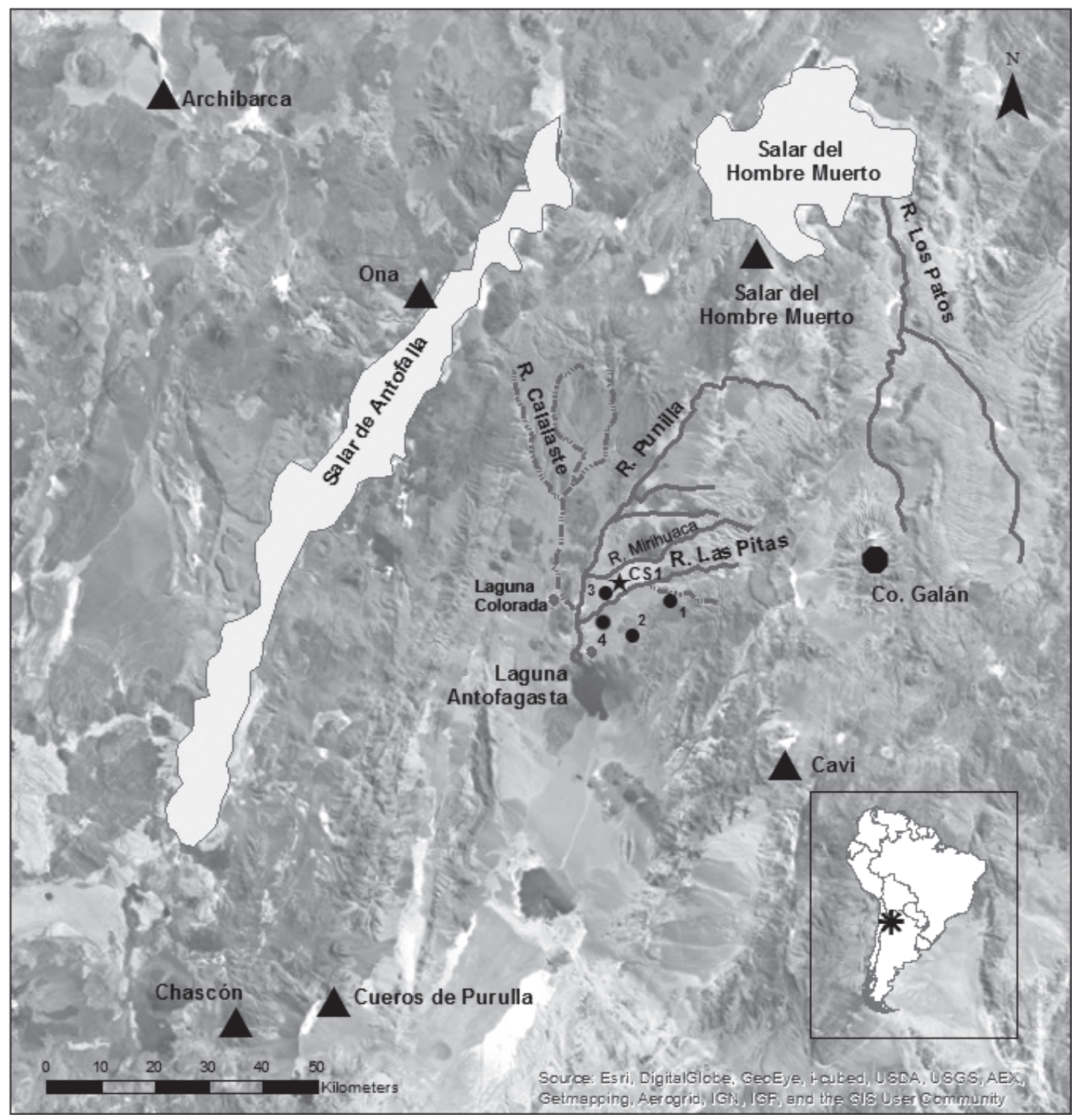

Figura 1. La región de Antofagasta de la Sierra, Catamarca, Argentina. Se denotan los sitios: Cueva Salamanca 1 (CS1), Quebrada Seca 3 (1), Peñas de la Cruz 1 (2), Peñas de las Trampas 1.1 (3) y Punta de la Peña 4 (4), y las fuentes de obsidiana (A): Archibarca, Ona, salar del Hombre Muerto, Laguna Cavi, Cueros del Purulla y Chascón.

The region of Antofagasta de la Sierra, Catamarca, Argentina. The following sites are shown: Cueva Salamanca 1 (CS1), Quebrada Seca 3 (1), Peñas de la Cruz 1 (2), Peñas de las Trampas 1.1 (3) and Punta de la Peña 4 (4), as well as the following obsidian sources ( $\mathbf{\Delta})$ : Archibarca, Ona, salar del Hombre Muerto, Laguna Cavi, Cueros del Purulla and Chascón.

2009) revelaron una secuencia de ocupaciones de antiguos cazadores-recolectores y de abandonos de esta cueva durante una fase árida identificada a partir de archivos sedimentarios en la Laguna Colorada $(12 \mathrm{~km}$ al oeste, Figura 1) entre aproximadamente 9.600-5.000 cal. a.p. (8.700 y 4.500 a.p.), con una breve fase húmeda ca. 7.000 cal. a.p. (6.000 a.p.) (Tchilinguirian y Morales 2013; Tchilinguirian et al. 2007). Pero a diferencia de Quebrada Seca 3, donde los fechados radiocarbónicos muestran pequeños hiatos durante el Holoceno Medio, Cueva Salamanca 1 registra ocupaciones reiteradas en un período de 1.000 años calendáricos (700 años radiocarbónicos), comenzando con su ocupación inicial ca. 9.000-8.000 cal. a.p. 8.100 a.p. hasta 7.400 a.p. (Tabla 1 y Figura 2). 
Tabla 1. Los fechados radiocarbónicos de Cueva Salamanca 1.

Radiocarbon dates from Cueva Salamanca 1.

\begin{tabular}{|c|c|c|c|c|}
\hline Capa & $\begin{array}{l}\text { Fechado convencional } \\
\qquad\left({ }^{14} \mathrm{C} \text { yr BP }\right)\end{array}$ & $\begin{array}{c}\text { Calibración en años calendario } \\
\qquad \begin{array}{c}(\mathrm{p}=0,95) \\
\left(\text { Cal a.p. }{ }^{*}\right)\end{array}\end{array}$ & Material & Laboratorio \\
\hline $2(1 \mathrm{a})$ & $4.460 \pm 30$ & $5.289-5.160 ; 5.140-5.100 ; 5.090-4.970$ & carbón & Beta-311872 \\
\hline $2(2 a)$ & $6.250 \pm 70$ & $6.897-7.226$ & carbón & LP-931 \\
\hline $2(3 a)$ & $7.410 \pm 100$ & 8.371-7.995; 7.990-7.981 & carbón & LP-615 \\
\hline $2(3 a)$ & $7.630 \pm 40$ & $8.510-8.500 ; 8.480-8.470 ; 8.460-8.380$ & carbón & Beta-311873 \\
\hline $2(4 a)$ & $7.500 \pm 60$ & $8.400-8.180$ & carbón & Beta-178223 \\
\hline $2(5 a)$ & $7.550 \pm 60$ & $8.420-8.200$ & carbón & Beta-178224 \\
\hline $2(6 a)$ & $7.540 \pm 50$ & $8.420-8.300 ; 8.250-8.220$ & carbón & Beta-280987 \\
\hline $2(7 a)$ & $7.620 \pm 60$ & $8.510-8.340$ & carbón & Beta- 178225 \\
\hline $2(8 a)$ & $7.870 \pm 50$ & $8.960-8.920 ; 8.860-8.830 ; 8.780-8.550$ & carbón & Beta-280988 \\
\hline $2(9 a)$ & $7.990 \pm 60$ & $9.020-8.630$ & carbón & Beta-280989 \\
\hline $2(10)$ & $8.100 \pm 50$ & $9.130-8.980$ & carbón & Beta-260687 \\
\hline
\end{tabular}

* Calibrados utilizando el programa Calib 6.0 para el hemisferio sur.

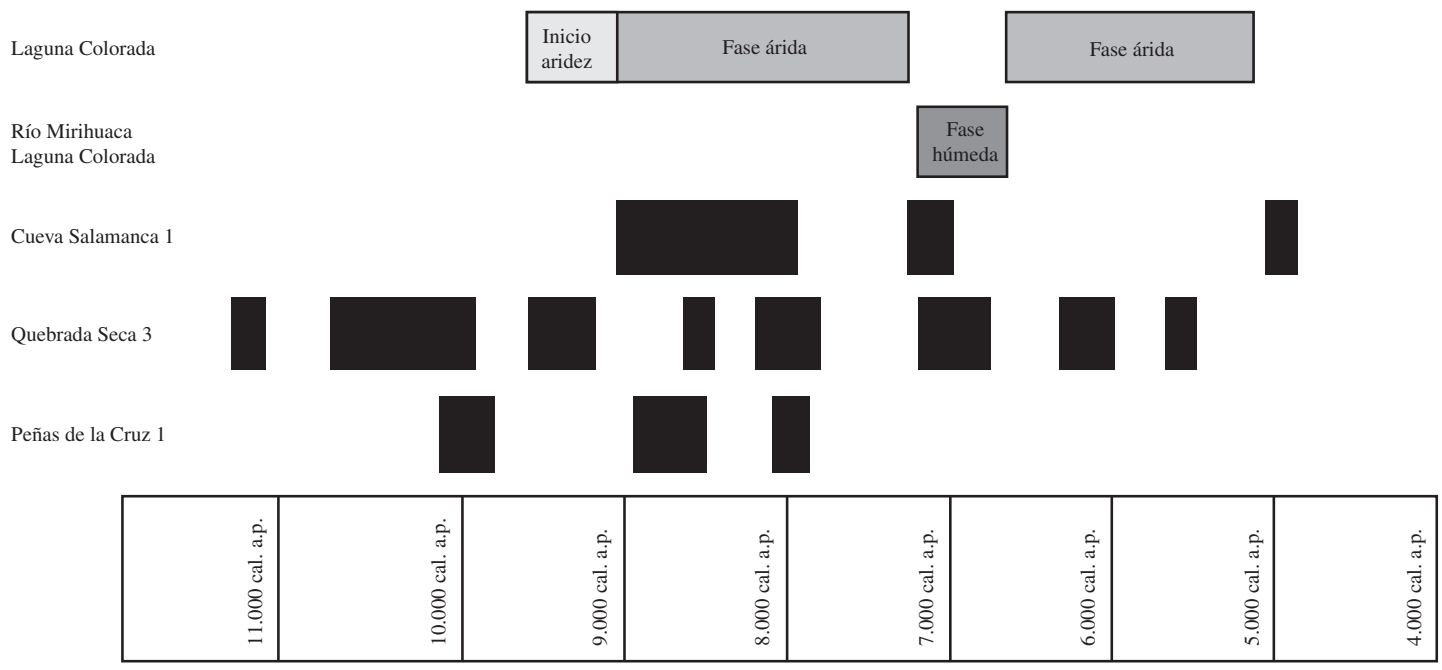

Figura 2. Ocupaciones por milenio en Cueva Salamanca 1 durante el Holoceno Medio expresados con fechados calibrados ( $1 \sigma$ ) usando Calib. Rev.6.1.0. (SHcal04.14c). Se denotan las ocupaciones en Quebrada Seca 3 y Peñas de la Cruz 1 a modo de comparación. Occupations per millennium at Cueva Salamanca 1 during the Middle Holocene, expressed in calibrated dates $(1 \sigma)$ using Calib. Rev.6.1.0 (SHcal04.014c). Occupations from Quebrada Seca 3 and Peñas de la Cruz 1 are shown for comparison.

Este trabajo se centra en las investigaciones realizadas en Cueva Salamanca 1. Las preguntas que guían este trabajo son: ¿Qué actividades se realizaron en Cueva Salamanca 1 durante este período?, y ¿qué permitió el retorno recurrente de grupos cazadores-recolectores nómades a esta cueva durante este período? Para abordar estas preguntas primero se presentará una síntesis de las investigaciones arqueológicas en Cueva Salamanca 1 y luego se examinarán los tipos de artefactos, ecofactos y estructuras halladas en Cueva Salamanca 1 para inferir las actividades desarrolladas allí. Finalmente se discutirá la trascendencia de estos hallazgos dentro de su contexto paleoambiental para lograr un mejor entendimiento del impacto de las condiciones áridas sobre las estrategias de asentamiento, movilidad y subsistencia de grupos cazadores-recolectores en el extremo SE de la Puna Salada. 


\section{Relieve, Topografía, Clima, Flora y Fauna}

La cuenca de la Laguna Antofagasta se encuentra en el borde SE de la Puna Salada. Este es un desierto de altura ubicado por sobre los 3.400 msm en un ambiente caracterizado por un relieve de planicies onduladas interrumpidas por conos volcánicos y cadenas de montañas que se elevan por sobre los $5.500 \mathrm{msm}$. Entre los cordones más altos se encuentra la Sierra de Calalaste, hacia el oeste, el cerro Galán, la sierra de Laguna Blanca y las Sierras Toconquis, hacia el este, y la cordillera de Buenaventura al sur. Los humedales ocupan las zonas más bajas del relieve, como ser el salar del Hombre Muerto al norte, el salar de Antofalla al noroeste, la Laguna de Antofagasta y la Laguna Colorada en el área de estudio, y el salar de Carachipampa, donde efectivamente se registran los valores altitudinales más bajos de la puna (3.200 msm), hacia el sur (García Salemi 1986).

La Laguna de Antofagasta es una cuenca endorreica que cubre un área de $2.500 \mathrm{~km}^{2}$ (Figura 1). El río más importante es el Punilla, que fluye hacia el $\mathrm{S}$. Este río tiene varios afluentes que fluyen de $\mathrm{E}$ a W: los ríos Las Pitas, Mirihuaca y Toconquis, con caudales que varían entre $2.000 \mathrm{~m}^{3} / \mathrm{h}$ y $700 \mathrm{~m}^{3} / \mathrm{h}$, respectivamente (Olivera et al. 2004). Estos cursos de agua son permanentes y de régimen nivopluvial. Sus fuentes se localizan en la vertiente occidental del cerro Galán (5.800 msm). Hacia el oeste se encuentran los ríos Calalaste y Nacimiento, tributarios del río Los Colorados (intermitente) que fluye a la Laguna Colorada. También hay una serie de lagunas de altura (sobre $4.200 \mathrm{msm}$ ) en la Sierra de Laguna Blanca y cerro Galán.

El clima en esta región es semiárido, con una marcada amplitud térmica tanto diurna como anual. Las estaciones son contrastadas, con precipitaciones líquidas y sólidas (granizo y nieve). Estas precipitaciones son estivales e inferiores a los 100 $\mathrm{mm}$ anuales, y decrecen progresivamente de este a oeste. Los vientos son frecuentes y alcanzan velocidades que superan $\operatorname{los} 60 \mathrm{~km} / \mathrm{h}$. La vegetación es xerófila y la cobertura vegetal es escasa (García Salemi 1986). La vegetación varía según la altura: en los fondos de cuencas y hasta los $3.900 \mathrm{msm}$ se encuentra el tolar, dominado por arbustos de los géneros Acantholippia, Adesmia, Baccharis, Fabiana y Parastrephia, y por sobre los $3.900 \mathrm{msm}$ se encuentra el pajonal dominado por especies de los géneros Festuca y Stippa. Las comunidades animales están compuestas por roedores (vizcachas, chinchillas), pájaros (flamencos, suris, guayatas), cánidos (zorro colorado), pumas y camélidos (vicuñas y llamas, y un reducido número de guanacos en la zona de Quebrada del Diablo, Depto. Antofagasta de la Sierra).

\section{Paleoambiente durante el Holoceno Medio}

Estudios paleoambientales en la Puna basados en evidencia multiproxy (sedimentos lacustres, glaciares, registros de vegetación, depósitos aluviales) reflejan una tendencia general hacia la aridización del ambiente y un descenso de la humedad ca. 9.500-4.500 cal. a.p. (8.500-4.000 a.p.). Las cuencas del Lago Titicaca (Bolivia), las Lagunas Miscanti y Laguna del Negro Francisco (Chile) y de la Laguna El Peinado (Argentina) reflejan una retracción de estos cuerpos lacustres entre 8.500 y aproximadamente 4.500 cal. a.p. (Valero Garcés et al. 1996; 2000). Los registros polínicos en la Laguna Seca (Chile) revelan un descenso en el polen arbóreo y un aumento de polen de gramíneas indicando una tendencia hacia condiciones de mayor aridez y temperatura después de 9.000 cal a.p. (Baied y Wheeler 1993). En El Aguilar (Argentina), Markgraf (1985) propuso que las condiciones de humedad del Holoceno Temprano perduraron hasta ca. 8.200 cal. a.p. (7.500 a.p.), y luego fueron seguidas por condiciones de aridez hasta 4.300 cal. a.p. (4.000 a.p.). Los registros polínicos de Tumbre (Chile) y de la Laguna Miscanti también muestran condiciones de sequedad entre ca. 7.200-4.200 cal. a.p. (6.200-3.800 a.p.) y 9.0006.900 cal. a.p. (8.000-6.100 a.p.), respectivamente (Graff 1992, citado en Grosjean et al. 2007).

Otros registros muestran que a pesar de la aridez también hubo breves períodos húmedos y fuertes tormentas. Períodos de mayor humedad se han registrado en la Laguna Seca entre 5.800$5.500 \mathrm{cal}$ a.p. (Baied y Wheeler 1993), en el salar de Atacama ca. 6.400 cal. a.p. (Grosjean y Núñez 1994) y también en el valle de Puripica (Chile) donde los depósitos aluviales muestran que hubo varias tormentas de moderada a fuerte severidad entre ca. 7.000-3.200 cal. a.p. (6.200 y 3.100. a.p.) (Grosjean et al. 1997; 2007). Además, durante el Holoceno Medio los glaciares en el Lago Taypi Chaka Kkota y Laguna Viscachani que se habían retractado en el Pleistoceno final, desaparecieron completamente hasta ca. 2.200 cal. a.p. (2.300 a.p.) (Abbott et al. 1997). En forma similar, en la zona de Pastos 
Chicos (Argentina) la fase húmeda del Holoceno Temprano finalizó ca. 8100 cal. a.p. (7.300 a.p.) y un ambiente árido prevaleció entre 8.100-6.800 cal. a.p. (7.300-6.000 a.p.) con eventos húmedos entre 7.800-7.200 cal. a.p. (7.000 y 6.300 a.p.). También en la quebrada de Lapao (Argentina) el análisis de diatomeas muestra que hubo condiciones húmedas que favorecieron el desarrollo de una vega entre $8.500-7.400$ a.p. (9.500 - 8.200 cal. a.p.) (Yacobaccio y Morales 2005).

Los datos paleoclimáticos disponibles para el período en cuestión en Antofagasta de la Sierra provienen de registros geomorfológicos y del análisis de los perfiles sedimentarios en Laguna Colorada y el río Mirihuaca (Figura 1). Se ha identificado una facie sedimentaria en Laguna Colorada indicando un paleoambiente húmedo entre ca. 11.200-9.600 cal. a.p. (9.900 y 8.700 a.p.). Una fase árida se ha identificado a partir de sedimentos asociados a una retracción lacustre entre 9.600-7.200 cal. a.p. (8.700-6.300 a.p.). En cambio, una fase breve y con mayor humedad se identificó ca. 7.200 cal. a.p. (6.300 a.p.) en Laguna Colorada. Asimismo, en el río Mirihuaca la presencia de paleosuelos fechados ca. 6.700 cal. a.p. (5900 a.p.) indica breves eventos húmedos. Luego habría un retorno a condiciones de mayor aridez entre 6.700 - 5.100 cal. a.p. (5.800-4.500 a.p.). Posteriormente, a partir de 5.000 cal. a.p. (4.500 a.p.) se habrían iniciado condiciones de mayor humedad en los ríos Punilla, Laguna Colorada y el río Mirihuaca (Olivera et al. 2004, 2006; Tchilinguirian 2009; Tchilinguirian y Morales 2013; Tchilinguirian et al. 2007).

En suma, la evidencia multiproxy en la Puna, tanto a escala regional como local, demuestra que hubo un gran descenso en la humedad efectiva entre 9.000-4.000 cal. a.p. (Grosjean 2001; Grosjean et al. 2007; Tchilinguirian y Morales 2013), sin embargo, ciertas localidades no fueron sensibles a estos cambios debido a procesos hidrológicos, geomorfológicos y geográficos particulares que permitieron una estabilidad en la base de recursos de los cuales dependieron los cazadores-recolectores de la época. Estas particulares circunstancias se discutirán más adelante.

\section{Ubicación del Sitio}

Cueva Salamanca 1 (CS1) se encuentra a 3.665 msm. Sus coordenadas son $26^{\circ} 01^{\prime} 22^{\prime \prime}$ S y $67^{\circ} 15^{\prime}$ 23 " W. Esta cueva yace en una cañada transversal a la quebrada del río Las Pitas, dentro de las peñas ignimbríticas que bordean la terraza del río. Esta cañada es el único punto de acceso entre el río y una planicie rocosa sobre los farallones de una extensión de aproximadamente $30 \mathrm{~km}^{2}$ delimitada al norte por el río Mirihuaca (Figura 1). En dicha planicie la topografía es muy irregular y ondulada con escasa cobertura vegetal, mayormente arbustos espinosos y aisladas gramíneas (tolar). Aquí, y a unos $400 \mathrm{~m}$ de CS1 se encuentra una cantera de vulcanita de alrededor de $1 \mathrm{~km}^{2}$ de superficie. CS1 está orientada al sur y tiene limitada visibilidad de la vega del río Las Pitas. Sus dimensiones son $11 \mathrm{~m}$ de ancho, $8 \mathrm{~m}$ de profundidad y $7 \mathrm{~m}$ de alto. El área de reparo dentro del sitio es de aproximadamente $77 \mathrm{~m}^{2}$ (Figura 3). Los remanentes de actividades humanas más visibles en la cueva consisten en un grabado cruciforme y varias pinturas rupestres en tonalidades rojizas, además de tres estructuras de piedra adosadas a la pared de la cueva.

\section{Métodos de Excavación}

Al momento se han descubierto aproximadamente $30 \mathrm{~m}^{2}$, alrededor de $40 \%$ del sitio. Las excavaciones procedieron por capas naturales usando el método de décapage, con documentación fotográfica y también registrándose en planta a escala 1:10 la procedencia dimensional del material recuperado in situ. Se han identificado tres unidades estratigráficas incluyendo una lente de ceniza volcánica que separa la capa 1 de la capa 2 . En cada una de las capas se distinguieron varios niveles o superficies de ocupación (Figura 4). En este trabajo se examinan los hallazgos de la capa 2 , por debajo de una capa de ceniza volcánica. Se incluye una breve descripción de la capa 1 para un mayor entendimiento de los períodos de ocupación y abandono del sitio.

\section{Capa $1\left(1^{\text {a) }}\right.$}

Esta capa superficial incluye muchos fragmentos caídos del techo de la cueva, y algunos tiestos de cerámica. Entre los hallazgos diagnósticos se encuentra una pequeña punta de proyectil lanceolada y apedunculada, con base convexilínea, de obsidiana, similar al tipo morfológico "Peñas Chicas E" (Hocsman 2006). Sobre esta superficie se hallaron tres estructuras de piedra (sin contenidos antrópicos) adosadas contra la pared del fondo de la cueva. 


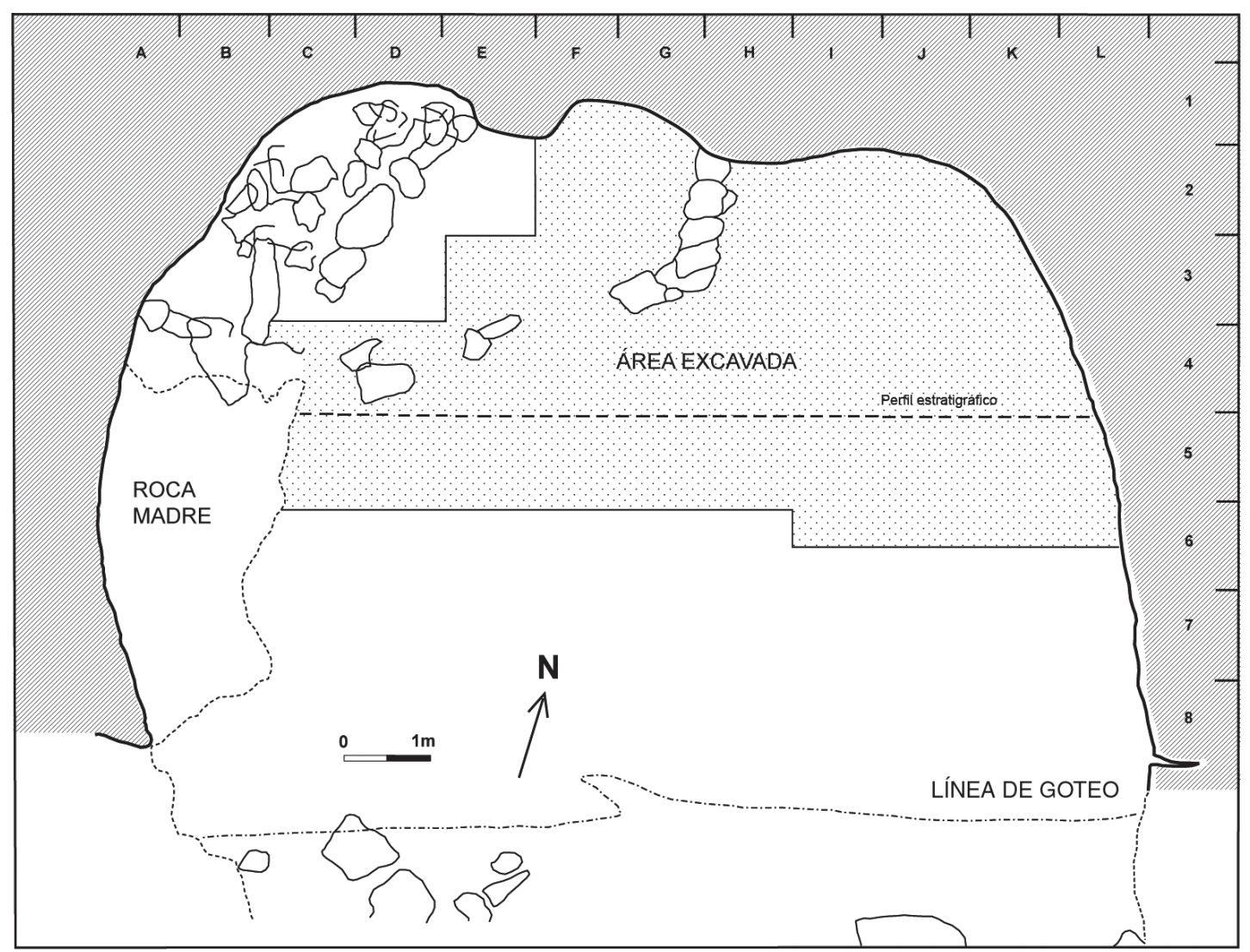

Figura 3. Planta de Cueva Salamanca 1, Antofagasta de la Sierra, Catamarca, Argentina.

Site plan from Cueva Salamanca 1, Antofagasta de la Sierra, Catamarca, Argentina.

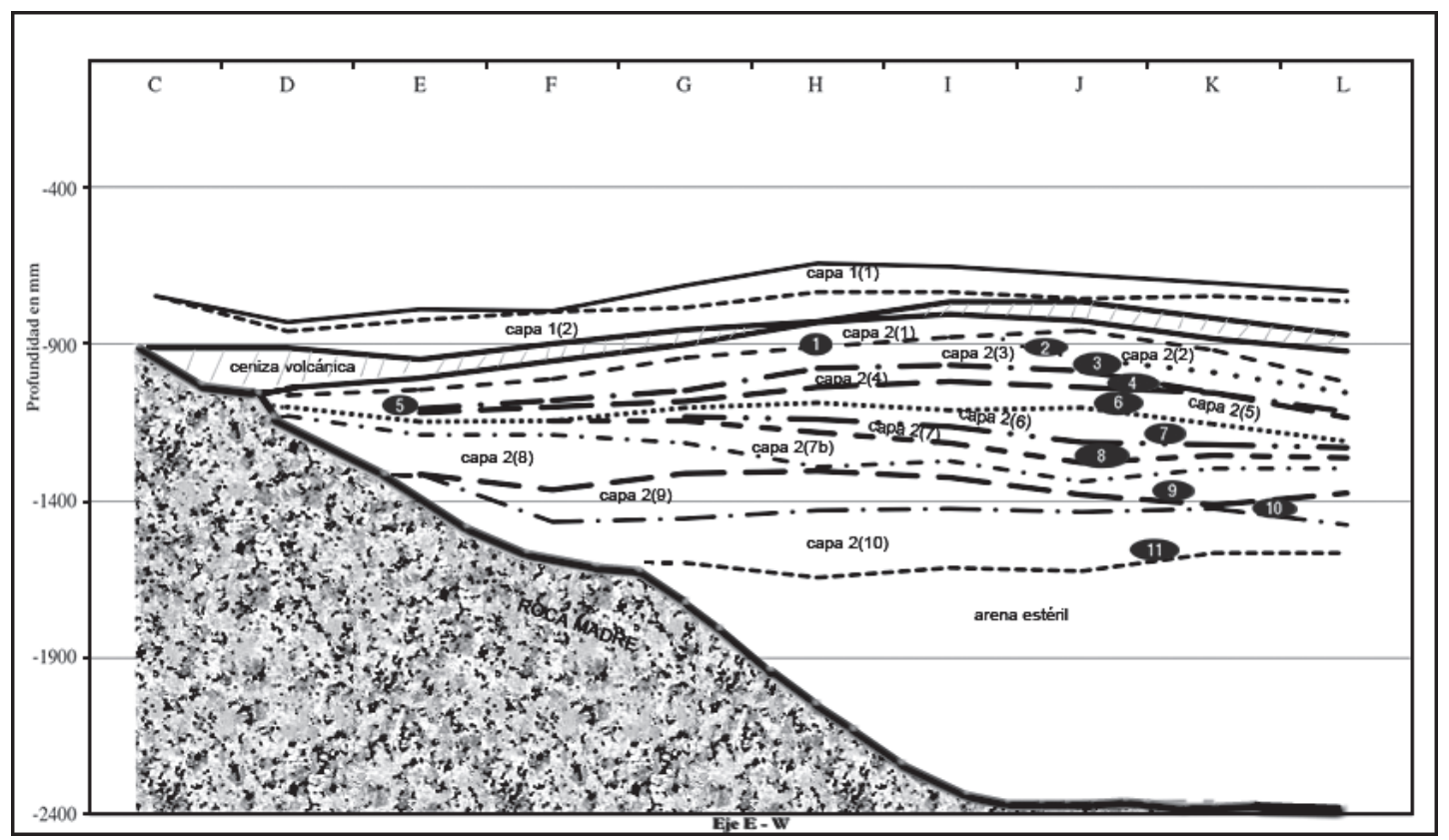

Figura 4. Estratigrafía de Cueva Salamanca 1 (las profundidades son en mm). Los círculos negros denotan los fogones cuyas numeraciones se muestran en Tabla 1.

Stratigraphy of Cueva Salamanca 1 (depths are shown in $\mathrm{mm}$ ). Black circles denote the hearths which are numbered in Table 1. 


\section{Capa $1\left(2^{\mathrm{a}}\right)$}

En esta capa se hallaron tallos y semillas de quinua (M. P. Babot comunicación personal 2012), manos de moler, un mortero, una estructura de cavado subcircular, y dos pequeños fogones. Las puntas de proyectil incluyen puntas lanceoladas apedunculadas de obsidiana (semejantes a las mencionadas supra) y una pequeña punta de proyectil con pedúnculo destacado y aletas/hombros entrantes, del tipo "Punta de la Peña C" que datan ca. 3.800 cal. a.p. (3.600 a.p.) (Hocsman 2006). Esta capa corresponde al período de transición entre el Holoceno Medio y el Tardío (Aschero y Hocsman 2011).

\section{Lente de ceniza volcánica}

Esta ceniza es blanca y de grano muy fino. Se encuentra de manera más continua en el sector W de la cueva (con una potencia entre 8 y $11 \mathrm{~cm}$ ), y en forma de depósitos o manchones discontinuos de hasta $2 \mathrm{~m}^{2}$ (con una potencia que varía entre 3 y $6 \mathrm{~cm}$ ) en el sector E de la excavación. La ceniza es estéril. Numerosos bloques caídos del techo de la cueva están recubiertos por esta ceniza, posiblemente a raíz de un terremoto que acompañó la erupción.

\section{Capa 2}

Esta capa arenosa se encuentra por debajo de la ceniza volcánica. Dentro de esta capa se han detectado diez niveles de ocupación (con potencias que varían entre 5 y $20 \mathrm{~cm})$, denominados sucesivamente capa 2(1) a capa 2(10). Por debajo de la capa 2(10) se ha detectado recientemente una capa de arena fina y estéril de $80 \mathrm{~cm}$ de profundidad antes de tocar la roca madre de la cueva. Por ende, la capa 2(10) consiste en la primera ocupación en CS1. La separación entre ellos se da a través de la presencia de delgadas lentes de sedimentos arenosos estériles de origen eólico. Cada uno de estos niveles tiene variados aportes antrópicos: estructuras de combustión, camadas de gramíneas, artefactos y desechos líticos, estructuras de cavado, restos faunísticos y vegetales, cestería, cordelería, cueros y fibras animales, de espinas de cactus y fragmentos de astiles de caña en excelente estado de preservación. Si bien la distribución espacial de estos restos en los niveles de la capa 2 es muy similar, ninguno es idéntico, ya que varían en su densidad (Pintar 2009).
Los fechados radiocarbónicos en esta capa varían entre ca. 9.000-4.900 cal. a.p. (8.100-4.460 a.p.) (Tabla 1). Al considerar los fechados calibrados (con rangos de $1 \sigma$ ), se observa la superposición de fechados correspondientes a las capas 2(10) a 2(3) entre ca. 9.000-8.000 cal. a.p., seguidos de un hiato de ca. 800 años calendáricos entre las ocupaciones de las capas 2(3) y 2(2), y seguido de otro hiato entre las capas 2(2) y 2(1) de aproximadamente 2000 años calendáricos (Tabla 1 y Figura 2).

Tanto en la capa 2(1) como 2(2) se observó que la superficie expuesta de varios artefactos líticos estaban marcadamente ventifactos, sugiriendo intensos vientos entre ca. 7.200 y 5.000 cal. a.p. (6.200-4.500 a.p.). Es muy probable que esto esté correlacionado con los ciclos de aridez detectados localmente en Laguna Colorada y en regiones aledañas (Grosjean et al. 2007; Núñez et al. 1999; Tchilinguirian y Morales 2013; Tchilinguirian et al. 2007; Valero-Garcés et al. 2000, entre otros).

\section{Actividades en Cueva Salamanca 1}

Para contestar las preguntas enunciadas al comienzo de este trabajo se discutirán los hallazgos en la secuencia de ocupaciones de capa 2(10) a 2(2) que corresponden al período de mayor aridez definido localmente (9.000-7.200 cal. a.p.). A continuación se presentan los resultados de análisis específicos realizados con los materiales hallados en CS1.

\section{(a) Actividades de producción de tecnología}

\section{Talla de materiales líticos}

Hasta el momento se han analizado más de 40.000 desechos líticos $(10 \mathrm{~kg}$ ) que incluyen casi 9.000 lascas enteras correspondientes a las capas 2(2) a 2(7) (Pintar 2013). Debe aclararse que el análisis lítico se ha realizado sobre $38 \%$ del área excavada (aproximadamente $12 \mathrm{~m}^{2}$ ) y no está concluido aún, ya que las áreas de talla en el sector W de la cueva todavía no han sido analizadas, por lo que estas conclusiones están sujetas a cambios, si bien las observaciones realizadas durante la excavación no prevén conclusiones sustancialmente distintas.

El análisis de desechos líticos en las capas analizadas reveló una gran similitud:

(a) baja frecuencia de lascas con corteza (menos del $1 \%$ de los desechos), 
(b) predominio de lascas internas (varía entre el $80 \%$ y $90 \%$ de los conjuntos líticos en cada nivel),

(c) mediana frecuencia de lascas de adelgazamiento (varía entre $7 \%$ y $17 \%$ ),

(d) alta proporción (> 80\%) de lascas muy pequeñas (midiendo lascas enteras solamente, promedian menos de $2 \mathrm{~cm}$ de largo y $2 \mathrm{~cm}$ de ancho),

(e) uso predominante $(>70 \%)$ de las vulcanitas locales (primordialmente la variedad 1 , disponible en varias canteras entre $0,5 \mathrm{~km}$ y $5 \mathrm{~km}$ de CS1, y la variedad 2, proveniente de una cantera a $8 \mathrm{~km}$ ),

(f) uso en proporciones variables (entre $10 \%$ y $30 \%$ de los desechos de talla) de las obsidianas no locales. Estudios de FRX realizados sobre 43 lascas provenientes de capa 2(7) muestran su origen en fuentes localizadas en el salar del Hombre Muerto, Ona y Cueros de Purulla (Pintar y Pessarossi-Langlois 2013). En tanto que una muestra de 25 artefactos (17 fragmentos de puntas de proyectil y 8 lascas) provenientes de capa 2(2) a capa 2(10) muestran su origen en las fuentes localizadas en Archibarca, salar del Hombre Muerto, Ona, Cueros del Purulla/ Chascón y Laguna Cavi (Figura 1 y Tabla 2). Todas estas fuentes de obsidiana se encuentran entre 110 y $35 \mathrm{~km}$ de CS1 (Pintar et al. 2011, 2012).

En cuanto a los artefactos formatizados, en todas las ocupaciones de la capa 2 (Tabla 3 ) se observa un predominio de artefactos bifaciales, correspondientes al continuum biface-punta de proyectil (entre $40 \%$ y 65\%), confeccionados mayormente en vulcanitas locales y relacionados a la producción, uso y recambio de puntas de proyectil en los sistemas de armas (lanzas y dardos) y posiblemente también a tareas de corte y punción. Al considerar los posibles modos de acción de los demás artefactos se observan instrumentos de corte (cuchillos, cuñas) y de raspado (raspadores, racletas, raederas, denticulados, muescas), probablemente asociados al trozamiento de carcasas, consumo de carne y grasa, y al trabajo de cueros y gamuzas.

\section{Acondicionamiento de las armas de caza}

En la Tabla 3 se ve la preponderancia de bases de puntas de proyectil sobre ápices (los limbos no se denotan en la tabla). Algunas de estas bases tienen sustancias adheridas (¿mástic?) y están asociadas a los fogones, posiblemente porque las tareas de mantenimiento de armas requerían del calor del fuego para ablandar el encastre del proyectil en el intermediario de astil. En capas 2(2) a 2(10) hay un número mínimo de 32 puntas de proyectil (esta estadística se basa en el recuento de bases de puntas de proyectil y puntas enteras). La morfología de estas puntas lanceoladas varía entre aquellas con base convexilínea y aquellas con base cóncava o escotada (Figura 5). Estas últimas puntas son similares a las puntas lanceoladas con pedúnculo esbozado y bordes dentados hallados en los sitios Quebrada Seca 3 y Peñas de la Cruz 1, descritos como tipos morfológicos QSC y QSD por Martínez (2005). Entre ca. 8.400-8.000 cal. a.p. (7.600-7.400 a.p.) hubo un notable predominio de este tipo de puntas de proyectil $(\mathrm{n}=18)$, en cuarcita $(n=2)$, vulcanita $(n=6)$ y obsidiana $(n=10)$. En cambio, las puntas de proyectil con base convexa $(n=3)$ son todas en vulcanita. Asociadas a estas puntas se han hallado intermediarios de astiles de cañas macizas (Chusquea lorentziana) en casi todas las ocupaciones de la capa 2 (Tabla 4), y también

Tabla 2. Procedencia de obsidianas según resultados de análisis FRX.

Provenience of obsidians according to XRF analyses.

\begin{tabular}{|c|c|c|c|c|c|}
\hline Capa & Laguna Cavi & Cueros del Purulla/Chascón & $\begin{array}{c}\text { Salar del Hombre } \\
\text { Muerto }\end{array}$ & Ona & Archibarca \\
\hline $2(3)$ & $\mathrm{x}$ & & $\mathrm{x}$ & $\mathrm{x}$ & $\mathrm{x}$ \\
\hline $2(4)$ & & & $\mathrm{x}$ & & $\mathrm{x}$ \\
\hline $2(5)$ & & & $\mathrm{x}$ & & \\
\hline $2(6)$ & & $\mathrm{x}$ & $\mathrm{x}$ & & \\
\hline $2(7)$ & & $\mathrm{x}$ & $\mathrm{x}$ & $\mathrm{x}$ & \\
\hline $2(8)$ & & $\mathrm{x}$ & & $\mathrm{x}$ & \\
\hline $2(9)$ & & & & $\mathrm{x}$ & \\
\hline $2(10)$ & & & & $\mathrm{x}$ & \\
\hline
\end{tabular}


Tabla 3. Clases de instrumentos líticos por capa. Stone tool classes by level.

\begin{tabular}{|c|c|c|c|c|c|c|c|c|c|}
\hline Instrumentos & $2(2)$ & $2(3)$ & $2(4)$ & $2(5)$ & $2(6)$ & $2(7)$ & $2(8)$ & $2(9)$ & $2(10)$ \\
\hline Buriles & 1 & & & & & & & & \\
\hline Cuchillos & 1 & & 1 & 1 & 1 & 2 & & 1 & \\
\hline Cuñas & 1 & 3 & & 3 & 3 & 1 & & & \\
\hline Raspadores & & & 1 & & & 2 & 1 & 1 & \\
\hline Racletas & 1 & & & & & & & & \\
\hline Raederas & & 1 & 3 & 2 & 3 & 1 & 2 & 2 & 1 \\
\hline $\begin{array}{l}\text { Lascas c/rastros de uso y/o } \\
\text { sustancias adheridas }\end{array}$ & 1 & 3 & 1 & & 3 & 2 & 2 & & 1 \\
\hline Denticulados & & & & & 2 & & & 1 & \\
\hline Muescas & & & & & 1 & & & & \\
\hline Núcleos & & 2 & 1 & & 1 & 2 & 1 & & 1 \\
\hline Percutores & & & & 1 & 3 & 1 & & & \\
\hline Retocadores de hueso & 2 & & & & & 2 & 3 & & \\
\hline Punzones de hueso & 1 & & & & & 2 & & & \\
\hline Piedras pulidas & 1 & & & & 1 & 4 & & & \\
\hline Manos de moler & & 1 & & & & & 1 ? & & \\
\hline Puntas de proyectil (ápices) & & & 1 & 1 & & & 1 & & \\
\hline $\begin{array}{l}\text { Puntas de proyectil } \\
\text { (con bases) }\end{array}$ & 6 & 5 & 3 & 5 & 7 & 4 & 1 & & 1 \\
\hline Preformas & 1 & 4 & 1 & & & 8 & & & \\
\hline Biface fg. & 2 & 7 & 5 & 5 & 9 & 16 & 7 & 2 & 1 \\
\hline Total & 18 & 26 & 17 & 18 & 34 & 47 & 19 & 7 & 5 \\
\hline
\end{tabular}

Tabla 4. Artefactos y ecofactos de materiales perecederos Artifacts and ecofacts in perishable materials.

\begin{tabular}{|c|c|c|c|c|c|c|c|c|c|}
\hline Capa: & $2(2)$ & $2(3)$ & $2(4)$ & $2(5)$ & $2(6)$ & $2(7)$ & $2(8)$ & $2(9)$ & $2(10)$ \\
\hline Manos de moler & & $\mathrm{x}$ & & & & & $\mathrm{x}$ ? & & \\
\hline Espinas de cactus & & & & & $\mathrm{x}$ & & $\mathrm{x}$ & & \\
\hline Cuentas & $\mathrm{x}$ ? & & & & & $\mathrm{x}$ & & $\mathrm{x}$ & \\
\hline Cestería & & $\mathrm{x}$ & & & & & & & \\
\hline Atados vegetales cortados & & & & & & & $\mathrm{x}$ & & \\
\hline Nudos de gramíneas & & $\mathrm{x}$ & & $\mathrm{x}$ & $\mathrm{x}$ & $\mathrm{x}$ & $\mathrm{x}$ & $\mathrm{x}$ & \\
\hline Hojas de cortadera & & & & $\mathrm{x}$ & $\mathrm{x}$ & $\mathrm{x}$ & $\mathrm{x}$ & & \\
\hline Hilo vena/tendón & $\mathrm{x}$ & & $\mathrm{x}$ & & $\mathrm{x}$ & $\mathrm{x}$ & $\mathrm{x}$ & $\mathrm{x}$ & \\
\hline Raquis plumas & & & & & & $\mathrm{x}$ & & & \\
\hline Plumas & $\mathrm{x}$ & & & & $\mathrm{x}$ & $\mathrm{x}$ & $\mathrm{x}$ & & \\
\hline Piedras quemadas & & $\mathrm{x}$ & $\mathrm{x}$ & $\mathrm{x}$ & $\mathrm{x}$ & $\mathrm{x}$ & $\mathrm{x}$ & & \\
\hline Pigmentos & $\mathrm{x}$ & $\mathrm{x}$ & $\mathrm{x}$ & $\mathrm{x}$ & & & & & \\
\hline Cordelería & $\mathrm{x}$ & $\mathrm{x}$ & $\mathrm{x}$ & $\mathrm{x}$ & & $\mathrm{x}$ & & & \\
\hline Tientos de cuero & & & & $\mathrm{x}$ & $\mathrm{x}$ & $\mathrm{x}$ & & & $\mathrm{x}$ \\
\hline Cueros de camélido & & $\mathrm{x}$ & $\mathrm{x}$ & $\mathrm{x}$ & $\mathrm{x}$ & $\mathrm{x}$ & $\mathrm{x}$ & $\mathrm{x}$ & $\mathrm{x}$ \\
\hline Cuero de zorro & & & & & & $\mathrm{x}$ & & & \\
\hline Sobador & & & & & & & $\mathrm{x}$ ? & & \\
\hline Estructuras de cavado & & $\mathrm{x}$ & $\mathrm{x}$ & & & $\mathrm{x}$ & $\mathrm{x}$ & & \\
\hline
\end{tabular}

un gancho de propulsor de piedra (Figura 6). La variabilidad en la morfología de las puntas de proyectil sumada a la presencia de astiles compuestos sugiere la coexistencia de dos sistemas de armas (lanza y propulsor). Estos astiles compuestos podrían ser intercambiables entre propulsor y lanza arrojadiza otorgando flexibilidad en los sistemas de caza, y permitiendo cazar vicuñas y guanacos en hábitats diferentes (Pintar 2008b).

La presencia de lascas de adelgazamiento y lascas pequeñas, sumados a los percutores y retocadores de hueso, apoyan la propuesta que tanto las tareas de talla de artefactos bifaciales -incluyendo los estadios finales del retoque y dentado de los filos 

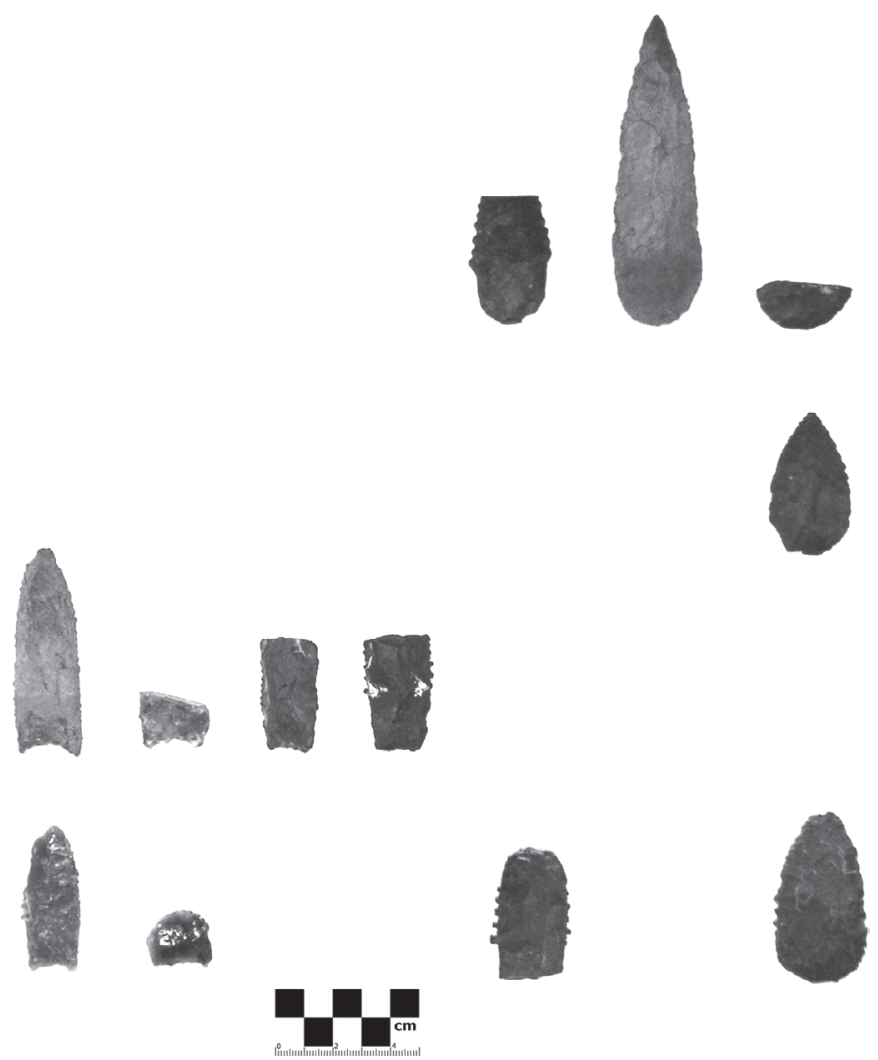

Figura 5. Las puntas de proyectil halladas en Cueva Salamanca 1, Catamarca, Argentina. De arriba hacia abajo: capa 2(2), capa 2(5), capa 2(6) y capa 2(7). Projectile points from Cueva Salamanca 1, Catamarca, Argentina. From top to bottom: level 2(2), level 2(5), level 2(6) and level 2(7).

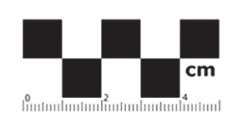

Figura 6. Dos astiles de caña Chusquea lorentziana y un gancho de propulsor de piedra hallados en Cueva Salamanca 1. De arriba hacia abajo: capa 2(3), capa 2(2) y capa 2(7).

Cane mid-shafts made of Chusquea lorentziana and a dart hook made of stone from Cueva Salamanca 1. From top to bottom: level 2(3), level 2(2) and level 2(7). 
en las puntas de proyectil-como el mantenimiento de las armas de caza se llevaron a cabo durante el período en estudio.

\section{(b) Actividades de subsistencia}

\section{Caza de guanacos, vicuñas, roedores y aves}

Recientes análisis osteométricos y foliculares muestran que vicuñas y guanacos fueron predominantemente los animales de presa cazados y transportados a CS1, y en menor medida chinchíllidos y cérvidos, si bien estos últimos no fueron cazados localmente (Marozzi 2012; Mondini et al. 2013; Reigadas 2012; Reigadas y Mondini 2010). Estos estudios reflejan que vicuñas y guanacos fueron cazados en los niveles de ocupación 2(2), 2(6), 2(7) y 2(10) en tanto que solamente se han identificado huesos de guanaco para los niveles 2(4) y 2(5), y solamente vicuña para el nivel 2(9) (Marozzi 2012). Si bien es posible que estos resultados sean un error de muestreo (la muestra analizada fue el 5\% del área excavada), también es posible que se haya cazado preferentemente uno u otro camélido en diferentes ocupaciones. Los grupos etarios identificados consisten en individuos juveniles-adultos, crías y nonatos. La presencia de estos últimos sugiere que el sitio fue ocupado durante la primavera-verano, aunque es posible que el sitio haya sido ocupado durante el otoño. El porcentaje de crías es del 50\% del MNI (número mínimo de individuos), y se ha inferido que se explotaron grupos familiares con una proporción de aproximadamente el 22\% NISP (número de especímenes identificados por taxón) de individuos inmaduros. Casi todas las partes esqueletarias están representadas, con lo que se infiere el transporte de carcasas completas al sitio (Mondini et al. 2013). Otros taxones identificados son las aves y los zorros en la capa 2(7).

Estudios realizados por Markgraf (1985) en El Aguilar y Barro Negro mostraron la retracción de las gramíneas del pajonal desde los $3.800 \mathrm{msm}$ por sobre los $4.100 \mathrm{msm}$, redundando en una mayor extensión de los arbustos del tolar y campo (Pintar 1996, 2009). Si bien este fenómeno pudo haber variado según la topografía en cada región (Tchilinguirian y Morales 2013), un incremento en la distribución del tolar en la región de Antofagasta de la Sierra habría favorecido al guanaco, que tiene una mayor tolerancia a la sequía y una dieta oportunista (González et al. 2006). Es posible entonces que a menores altitudes dentro de la Puna el guanaco haya desplazado a la vicuña. Estudios de isótopos $\delta 13 \mathrm{C}$ y $\delta 14 \mathrm{~N}$ en huesos de camélidos de CS1 muestran una ingesta mayor de plantas $\mathrm{C} 4$ en un hueso identificado como guanaco comparado a un hueso identificado como vicuña. Si bien la muestra de estudio es pequeña, estos resultados sugieren que los guanacos pudieron provenir de áreas donde habría más plantas C4 (áreas más bajas) que en los sectores de altura donde se alimentarían las vicuñas (Mondini et al. 2010). La planicie sobre CS1 pudo haber sido un territorio de tropillas de guanacos que usaban la cañada de Salamanca para bajar al río a beber agua. Los estudios de isótopos también sugieren que los cazadores de CS1 habrían utilizado territorios de caza diferentes para vicuñas (zonas altas, dentro del pajonal) y para guanacos (zonas más bajas, dentro del tolar). El conocimiento de la etología de estos camélidos por parte de los cazadores de la época habría permitido la planificación de cacerías en las inmediaciones de CS1, donde hay suficientes hondonadas y promontorios que pudieron haber funcionado como escondrijos desde los cuales se lanzaron las armas de caza, como a $8 \mathrm{~km}$ cerca del sitio Quebrada Seca 3, donde hay varios parapetos de caza (Aschero y Martínez 2001).

\section{Recolección de gramíneas, leña y raíces comestibles}

Los artefactos y ecofactos de materiales perecederos (Tabla 4), invisibles en muchos sitios pero en muy buen estado de preservación en Cueva Salamanca, reflejan otras actividades realizadas por un grupo social (hombres, mujeres y niños). Entre los abundantes vestigios vegetales recuperados en capas 2(2), 2(3) y 2(4) se han identificado tanto plantas que provienen del tolar (inmediatamente rodeando el sitio hoy y durante el Holoceno Medio), pajonal (aguas arriba, probablemente $8-10 \mathrm{~km}$ de distancia) y también de la vega del río, a saber: (a) maderas leñosas correspondientes a Adesmia horrida (tolar y pajonal) y Fabiana bryoides (pajonal), (b) carbón de las especies Baccharis incarum (pajonal) y Sisymbrium philippianum (tolar), (c) gramíneas de la especie Deyeuxia eminens var fulva (vega) utilizadas para la confección de estructuras (para sentarse, trabajar o dormir) y Festuca sp. (pajonal) (Pintar 2004; Rodríguez et al. 2003). Además se han identificado (d) hojas de Cortaderia sp. y (e) restos de tallos con raíz de Baccharis sp. en capas 
2(5), 2(6) y 2(8) (Rodríguez y Pintar 2013). Muchas de las plantas cuentan con raíz y tallos con flor, particularmente las estructuras de gramíneas, lo que sugiere ocupaciones de primavera-verano y posiblemente otoño. Finalmente, se han hallado vainas de Hoffmansegia eremophila que tiene tubérculos comestibles en capa 2(4) (Pintar 2004).

\section{Procesamiento por molido}

Los rastros de uso y las sustancias adheridas a una mano de moler en capa 2(3) (Tabla 3), atestiguan el procesamiento por molido de tubérculos y/o raíces no diferenciadas, hojas de Poaceae, fruto u hoja de Fabaceae, corteza del fruto de Lagenaria siceraria, y hoja y/o pecíolo de Arecaceae aff. Acrocomia sp. (Babot 2011). En cuanto a los tubérculos, éstos tienen un alto contenido de carbohidratos y pueden ser almacenados. También pudieron jugar un rol en la supervivencia infantil, ya que las "papillas" son suplementos dietarios durante y después del período de lactancia (Pintar 2008a). El único tubérculo silvestre registrado en Antofagasta de la Sierra por la autora es la "papa cuchi", de $3 \mathrm{~cm}$ de diámetro que crece en terrenos arenosos, y tiene un sabor amargo. El nombre local corresponde a Hoffmansegia falcaria (Cabrera 1957).

\section{Cocción de alimentos}

Los fogones tienen fondo en cubeta (con potencia entre 4 y $12 \mathrm{~cm}$ ) y han causado la rubefacción del sedimento que los rodea. Se encontraron pocos huesos dentro de los fogones, aunque hay huesos quemados en todos los niveles de ocupación. Además hay piedras esferoidales quemadas con sustancias adheridas en áreas alejadas del fogón (Tabla 3), posiblemente usadas en la cocción indirecta donde primeramente se calientan las piedras en las brasas y luego se introducen a una cesta (o contenedor) que contiene un caldo o una sopa/guiso/papilla. Hay datos etnográficos sobre el uso de piedras calientes en cestas coiled para hervir guisos entre los Havasupai, Miwok y otros grupos originarios de Norteamérica (Barrett y Gifford 1933), por lo que se plantea aquí la posibilidad de que este sistema también estuviera en uso en la Puna. Este sistema es diferente al sistema de cocción sobre piedras calientes en estructuras cavadas (Thoms 2009), y permite hervir carne, hueso y grasa, además de plantas, raíces y tubérculos que no serían posibles de consumir si no fueran sometidos al calor. En este sentido, esta tecnología de cocción permitió extraer grasa de los huesos, diversificando, intensificando y complementando una dieta rica en proteínas (carne) con grasas y carbohidratos (Speth 2010), posiblemente contribuyendo a la supervivencia infantil (Pintar 2009).

\section{(c) Actividades de producción de tecnofacturas}

\section{Cestería}

Se halló un solo fragmento de cestería en la capa 2(3) (Tabla 4). Sus dimensiones son: $3,6 \mathrm{~cm}$ x 0,6 $\mathrm{cm} \times 0,5 \mathrm{~cm}$ (Figura 7). Se trata de un fragmento de una cesta, del tipo conocido como espiral (coiled). Como urdimbre se utilizó un haz de pastos (bundle foundation) y como trama una serie de puntadas simples (simple stitch) muy próximas a sí mismas. Las puntadas están intencionalmente bifurcadas en la superficie convexa de la pieza (Edward Jolie, comunicación personal 2011). La forma de la cesta es difícil de determinar, sin embargo, parece que este tipo de cestería en espiral ha sido manufacturado casi exclusivamente para contenedores (Adovasio 1977). Su uso podría estar en relación con la cocción de alimentos, ya que está parcialmente chamuscado.

En cuanto a los nudos de gramíneas y el fragmento de cesta, éstos son similares a aquellos que han sido descritos para Quebrada Seca 3 (Rodríguez 1999), con fechados ca. 8.400-7.900 cal. a.p. (7.700 y 7.100 a.p.). Los punzones hallados en CS1 podrían haberse utilizado para la confección de cestas coiled,
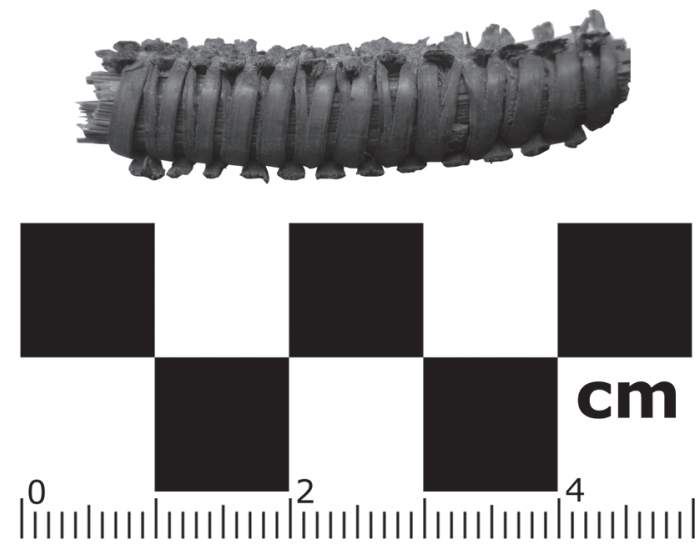

Figura 7. Fragmento de cestería de Cueva Salamanca 1, capa 2(3). Basketry fragment from Cueva Salamanca 1, level 2(3). 
para introducir la puntada (de un ancho de $2 \mathrm{~mm}$ aproximadamente) y producir el bifurcamiento en la superficie exterior de las cestas. Alternativamente se podrían haber utilizado las espinas de cardón (que se mencionan en acápite aparte).

\section{Trabajo de cueros}

CS1 cuenta con cueros con pelo, un cuero gamuzado con tres ojales en capa 2(3) (Figura 8) y tientos de vicuña y guanaco (Tabla 4) (Reigadas 2012). Además hay dos orejas de zorro (Dussicyon culpaeus) y un cuero con pelo de zorro en la capa 2(7). Estos cueros pudieron ser trabajados en el sitio, y usados para confeccionar vestimenta o calzado. La correspondencia entre los cueros y las raederas, raspadores y sobadores en las capas de ocupación apoyan esta tesitura.

\section{Hilado de cordeles}

Estos son de fibra de camélido, de diferentes longitudes, con y sin nudo, hilados en "Z". Su presencia (Tabla 4) sugiere el hilado de estos cordeles in situ para hacer sogas, mantas, etcétera.

\section{Tejido y/o costura}

Las espinas de cardón Trichocereus pasacana, podrían haberse usado en actividades de costura, tejido o cestería (Tabla 4). Estos cardones crecen

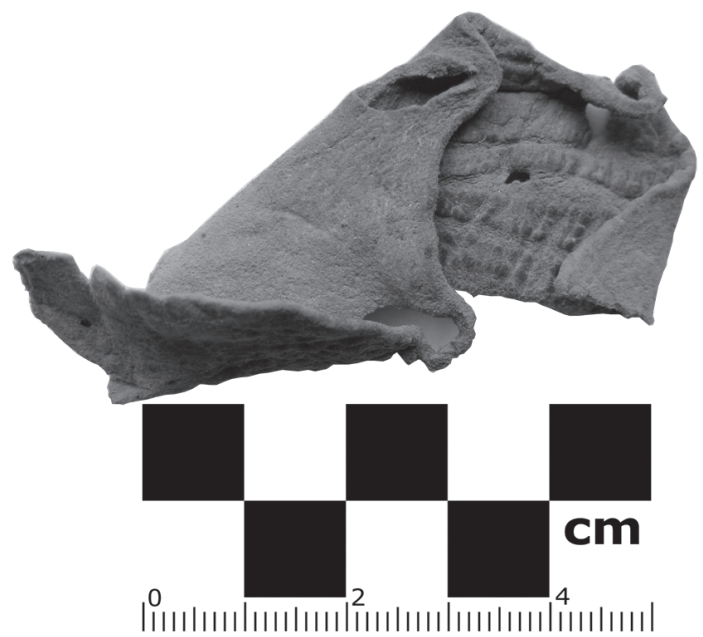

Figura 8. Fragmento de cuero gamuzado de Cueva Salamanca 1, capa 2(3).

Suede fragment from Cueva Salamanca 1, level 2(3). en las altas laderas y quebradas que acceden a la puna, a una distancia mínima de $120 \mathrm{~km}$ de CS1. Espinas similares han sido halladas en Quebrada Seca 3, en el nivel 2 b11 ca. 7.900 cal. a.p. (7.100 a.p.) (Rodríguez 1999) y en Peñas de la Cruz 1.1 con un fechado ca. 8.600-8.000 cal. a.p. (7.900-7.200 a.p.) (Martínez 2005). Su uso podría estar asociado a costura de vestimenta y tejidos de malla (bolsas de red).

Otras actividades inferidas a partir de restos hallados en CS1 incluyen, pero no se limitan a, las siguientes actividades:

\section{Armado/uso de collares con cuentas de semi-} llas o valva

Varias cuentas de semillas alóctonas y no identificadas fueron halladas en capas 2(8), 2(9) y 2(10). Asimismo, una cuenta de valva (posiblemente marina) con dos agujeros fue hallada en capa 2(7) (Figura 9). Cuentas similares han sido halladas en el sitio Peña de las Trampas 1.1 en asociación a los restos humanos hallados dentro de dos estructuras funerarias ca. 9.400-9.000 cal. a.p. (8.400-8.200 a.p.) (Martínez 2012).

6. Fabricación de faldellines, cobertores púbicos y/o esteras con fibra vegetal

Los atados de gramíneas bien pudieron servir para realizar estas tecnofacturas.

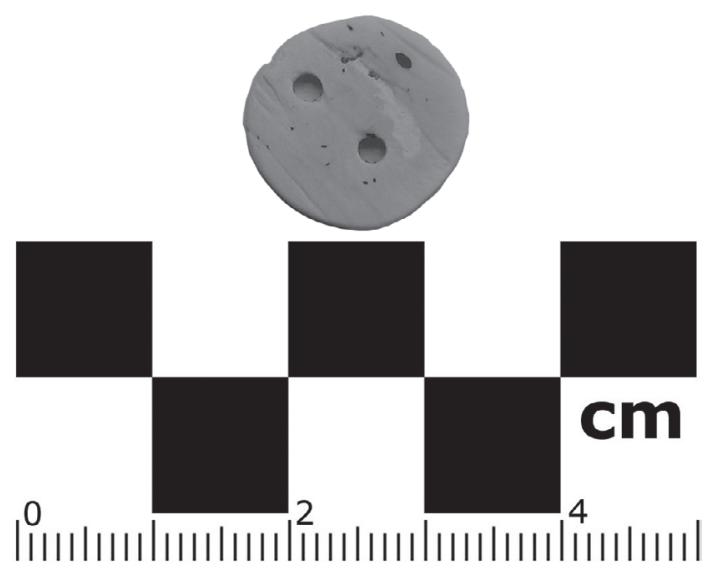

Figura 9. Cuenta de valva en Cueva Salamanca 1, capa 2(7). Shell bead from Cueva Salamanca 1, level 2(7). 
7. Fabricación de vinchas, penachos, pectorales y/o faldellines de plumas

El raquis de una pluma de suri local (Pterocnemia pennata) en capa 2(9) es similar a aquellos en los faldellines asociados a restos humanos en Peña de las Trampas 1.1 (Martínez 2012).

\section{Uso de pigmento rojo para teñido de cueros $y$ arte rupestre}

Fragmentos de pigmento rojo han sido hallados en todas las capas de CS1. Dos fragmentos de soporte del techo de la cueva con manchas de pigmento rojo han sido hallados bajo la capa de ceniza volcánica, en capa 2(1). Esto sugiere la ejecución de alguna forma de arte rupestre previo a ca. $4.900 \mathrm{cal}$. a.p. (4.500 a.p.).

\section{(d) Actividades de construcción de estructuras}

La presencia de fogones y camadas de gramíneas alrededor de todos los fogones en todos los niveles de ocupación, además de las estructuras de cavado (vacías) en las capas 2(3), 2(4), 2(7) y 2(8), son ejemplos de actividades que acondicionaron del espacio y limitaron o facilitaron las áreas de trabajo.

\section{Discusión}

\section{Cueva Salamanca 1: un espacio favorable}

La primera pregunta que este trabajo aborda son las actividades realizadas en CS1. Los datos presentados supra muestran que a lo largo de la secuencia ocupacional analizada en Cueva Salamanca 1 se desarrollaron tanto actividades de subsistencia relacionadas a la caza (mayormente de camélidos) y recolección (gramíneas, leña, raíces) como a actividades de producción de tecnología (puntas de proyectil, artefactos de corte y raspado) y de tecnofacturas (trabajo de cueros, cestería). Es decir, la evidencia presentada sugiere que la función del sitio no varió significativamente entre 9.000-7.100 cal. a.p. (8.100-6.200 a.p.), y particularmente entre 8.400-7.100 cal. a.p. (7.600-6.200 a.p.). De modo que CS1 proporcionó un espacio favorable para el emplazamiento de un campamento de un grupo residencial doméstico: tiene sombra todo el año, lo que provee especiales ventajas en el verano, y ofrece protección del viento. Además, el área de reparo $\left(77 \mathrm{~m}^{2}\right)$ que brinda permitió la realización de tareas en toda la cueva. CS1 también habría constituido un espacio propicio desde donde partieron grupos de caza y recolección en busca de recursos alimenticios, agua, leña y materias primas para confeccionar estructuras, tecnofacturas vegetales y artefactos líticos, la mayoría de los cuales pudieron ser explotados dentro de un rango de menos de $10 \mathrm{~km}$ de Cueva Salamanca 1, con la excepción de las obsidianas y los recursos extrapuneños (Tabla 5). En la planicie rocosa sobre CS1 habría tropillas de guanacos, y sus predadores los zorros (Novaro 2009). Restos de ambos han sido hallados en CS1. Si estos guanacos exhibieron la misma fidelidad territorial que los guanacos actuales (Young y Franklin 2004), esta planicie habría sido un coto de caza de guanacos. En cambio, la caza de vicuñas se habría realizado a través de partidas de caza aguas arriba del río Las Pitas, en la zona de pajonal de las quebradas superiores del río Las Pitas y Quebrada Seca $(\sim 8-10 \mathrm{~km})$, con estrategias descritas por Aschero y Martínez (2001).

Tabla 5. Distancia de CS1 a los recursos utilizados

Distances from CS1 to the resources used.

\begin{tabular}{cc}
\hline Distancia de CS1 & Recursos \\
\hline $0-8 \mathrm{~km}$ & $\begin{array}{c}\text { guanacos, zorros, roedores, suris, leña, tubérculos, gramíneas, } \\
\text { cortaderas, vulcanitas, cuarcitas, cuarzo } \\
8,1-10 \mathrm{~km} \\
35-110 \mathrm{~km}\end{array}$ \\
$>120 \mathrm{~km}$ & $\begin{array}{c}\text { vicuñas, zorros, roedores, suris, leña, tubérculos, gramíneas, } \\
\text { vulcanitas } \\
\text { obsidianas, camélidos }\end{array}$ \\
& $\begin{array}{c}\text { recursos extrapuneños: Trichocereus pasacana, Chusquea } \\
\text { lorentziana, semillas, valvas, ¿cérvido? }\end{array}$ \\
\hline
\end{tabular}




\section{Ocupaciones y abandonos durante una fase árida}

La segunda pregunta que aborda este trabajo se refiere a los factores que permitieron la recurrente ocupación de CS1 durante un período de aridez local. Los fechados radiocarbónicos en CS1 (Tabla 1 y Figura 2) muestran una serie de ocupaciones y abandonos a lo largo de toda la columna estratigráfica. El primer período de ocupación coincide con el comienzo de la fase árida en la zona de Antofagasta de la Sierra hacia 9.700 cal. a.p. (8.700 a.p.). A partir de las primeras ocupaciones hubo un uso repetido de la cueva (sin hiatos) entre ca. 9.000 y 8.000 cal. a.p. (8.100-7.400 a.p.). La cueva luego fue abandonada durante 800 años calendáricos y posteriormente reocupada ca. 7.200 cal. a.p. (6.200 a.p). De forma similar, las ocupaciones en otros sitios distantes $8 \mathrm{~km}$ también se interrumpieron ca. 8.000 cal. a.p., como Quebrada Seca 3 (ubicada en una quebrada de altura, a $4.100 \mathrm{msm}$ ) y en Peñas de la Cruz 1 (ubicada en una quebrada intermedia, a $3.660 \mathrm{msm}$ ) (Aschero 1988; Martínez 2005). Este último sitio no fue reocupado, en tanto que las ocupaciones en Quebrada Seca 3 se reanudaron aproximadamente 7.200 cal. a.p. Las reocupaciones de CS1 y de Quebrada Seca 3 coinciden con una breve fase húmeda identificada en el río Mirihuaca y en Laguna Colorada. Luego, y a diferencia de Quebrada Seca 3 , CS1 fue de nuevo abandonada por alrededor de 2.000 años calendáricos hasta aproximadamente 5.000 cal. a.p. (4.500 a.p.), momento en el cual finaliza la fase árida (Tchilinguirian et al. 2007; Tchilinguirian y Morales 2013) en tanto que Quebrada Seca 3 fue ocupada en forma intermitente durante este período. Esta sucesión de ocupaciones y hiatos en CS1 merece mayor atención debido al entorno de aridez en la cuenca de la Laguna de Antofagasta.

\section{Continuidad en el uso del espacio y en el diseño de puntas de proyectil}

La evidencia presentada muestra una reutilización de la cueva por parte de un grupo cazador-recolector durante las estaciones de primavera-verano (y posiblemente otoño) según los indicadores arqueobotánicos y arqueofaunísticos mencionados supra. En particular entre ca. 8.6008.000 cal. a.p. (7.900-7.400 a.p.), capas 2(8) a 2(3), se observa una similar organización del espacio en cuanto al consistente emplazamiento de los fogones en el sector E de la cueva y área de talla en el sector central de la cueva, además de la distribución de las camadas de gramíneas alrededor de los fogones. El diseño de las puntas de proyectil lanceoladas con limbos denticulados y bases escotadas en las capas 2(7) a 2(3), fechadas entre 8.400-8.000 cal. a.p. (7.600 y 7.400 a.p.), guarda similitud con los tipos morfológicos QSC y QSD definidos para Quebrada Seca 3 y Peñas de la Cruz 1 entre 8.5008.000 cal. a.p. (7.760 y 7.220 a.p.) (Martínez 2005), aunque existe cierta variabilidad respecto de estos tipos morfológicos, p.ej., bordes subparalelos del pedúnculo, pedúnculos más anchos, y el predominante uso de obsidianas para su confección (Pintar et al. 2012). Estas puntas de proyectil perduran en CS1 por 400 años calendáricos insinuando una variación estilística que pudo ser resultado de gestos técnicos aprendidos y heredados propios del grupo social que ocupó esta cueva. Etnográficamente se conoce de la asociación de grupos con fuentes de agua y su "tenencia" a lo largo de varias generaciones, p.ej., los Kung, quienes mantienen una relación con ciertos ojos de agua entre 30 y 50 años (Lee 1976) y varios grupos australianos que definen sus territorios a base de ojos de agua, pequeños arroyos o lagunas (Davidson 1928). Esta consistente similitud en el diseño de puntas de proyectil sugiere la planificación de retornos de grupos cazadores-recolectores que estarían ligados a la presencia de una base de recursos confiable.

\section{Estabilidad ocupacional y uso del paisaje}

La relativa estabilidad ocupacional en CS1 entre 9.000 y 8.000 cal. a.p. (8.100 y 7.400 a.p.), así como los hiatos de ocupación son significativos. A pesar de la ausencia de archivos sedimentarios con una profundidad temporal mayor a ca. $6.700 \mathrm{cal}$. a.p. (6.000 a.p.) en el río Las Pitas (Tchilinguirian et al. 2007; Tchilinguirian 2009), el archivo sedimentario en CS1 (3.665 msm) lleva a inferir la existencia de un curso de agua en este río durante su ocupación, resaltando que hubo variaciones climáticas a nivel interfluvial, altitudinal y microrregional. ¿Pero cuál fue la variación en otras áreas de la puna meridional argentina, de las cuales se desconocen los datos ambientales, y cómo afectó esta fase árida al uso del paisaje?

Las puntas de proyectil de obsidiana presentes en CS1 pueden utilizarse como un dato indirecto para contestar esta pregunta. Estas obsidianas 
proceden de Archibarca (110 km NW), Ona (60 km NW), salar del Hombre Muerto (65 km NNE), Cueros del Purulla/Chascón (90km SW) y Laguna Cavi (35 km SE)( Figura 1). La variabilidad en su uso puede aportar datos sobre las estrategias de movilidad de grupos cazadores. En el período 8.400-8.000 cal. a.p. (7.600-7.400 a.p.) el 56\% de las puntas de proyectil con base escotada son de obsidiana. Sin embargo, el patrón de uso de las fuentes de obsidiana no fue constante (Tabla 2; Figura 10), por ejemplo, en las primeras ocupaciones de CS1 ca. 9.000-8.500 cal. a.p. se registra el uso de las fuentes Ona y Cueros de Purulla/ Chascón, en tanto que ca. 8.400-8.000 cal. a.p. se registra el uso de las fuentes localizadas en el salar del Hombre Muerto, Cavi, Archibarca, además de Cueros de Purulla/Chascón y Ona. Si bien la presencia de estas obsidianas en Cueva Salamanca se podría deber a diferentes factores, por ejemplo viajes logísticos desde CS1 a las fuentes, previas bases residenciales en esas regiones, previos viajes logísticos a esas zonas desde otras bases residenciales, y otras explicaciones incluyendo factores sociales (Pintar 2008c), el patrón de uso sugiere una movilidad a grandes distancias. Sin embargo, los rangos de movilidad pudieron verse modificados por la aridez del Holoceno Medio.

El análisis de las fuentes de obsidiana representadas en CS1 permite analizar el rango de movilidad de cazadores-recolectores y potencialmente las condiciones alrededor de las fuentes de obsidiana a una escala de mayor resolución temporal que en sitios con ocupaciones más esporádicas e interrumpidas. Más específicamente, se propone que los períodos de desuso de las fuentes representadas en CS1 estarían indicando condiciones ambientales inestables en esas regiones entre 9.000 y 8.000 cal. a.p. Esta situación se ve parcialmente corroborada por los estudios paleohidrológicos que muestran bajos niveles lacustres en la Laguna El Peinado, al sur del salar de Antofalla, antes de 4.400 cal. a.p. (4.000 a.p.) (Valero-Garcés et al. 2000). Las fuentes Cueros de Purulla/Chascón se encuentran a unos $25 \mathrm{~km}$ de distancia. Es posible que las facies sedimentarias en esta laguna que se correlacionan con el Holoceno Medio (sin posibilidad de fechar) y que indican niveles lacustres más altos podrían estar indicando períodos durante los cuales las condiciones climáticas al sur del salar de Antofalla fueron más húmedas, o sea, períodos cuando las fuentes en Cueros de Purulla/Chascón pudieron haber sido utilizadas (entre ca. 8.6808.610 cal. a.p.). La no utilización de estas fuentes con posterioridad a estas fechas podría marcar momentos de retracción lacustre en El Peinado. En forma similar, el uso de las fuentes localizadas en Archibarca y Ona, que se sitúan al NW del salar de Antofalla, pudieron estar restringidos a

Archibarca

Cavi

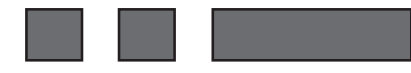

Salar del Hombre Muerto

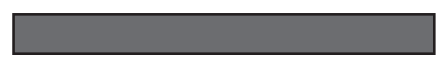

Cueros de Purulla/Chascón

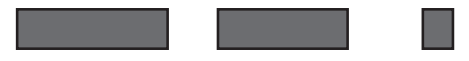

Ona

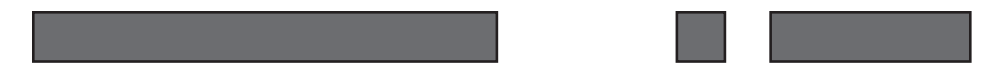

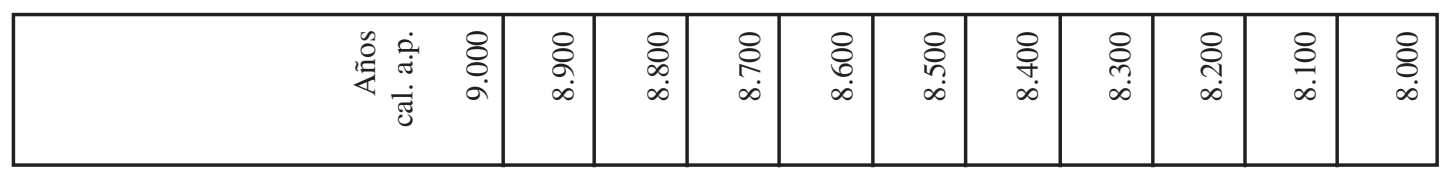

Figura 10. Uso de las fuentes de obsidiana tomando en cuenta los rangos $(1 \sigma)$ de los fechados calibrados.

Use of obsidian sources including ranges $(1 \sigma)$ of calibrated dates. 
décadas húmedas. O sea, la no representación de estas dos fuentes en CS1 podría estar indicando que esas localidades con fuentes de obsidiana fueron abandonadas durante décadas y centenios áridos (Pintar et al. 2012).

El período entre 8.500 cal. a.p. (ca. 7.600 a.p.) marca el comienzo del uso sincrónico de todas las fuentes, si bien con breves interrupciones de algunas décadas. La excepción es la fuente localizada en el salar del Hombre Muerto que fue utilizada sin interrupciones entre 8.500-8.000 cal. a.p. Esta circunstancia podría deberse al hecho que el río Los Patos, que fluye a este salar, tiene su vertiente en el cerro Galán (al igual que el río Las Pitas, donde se encuentra CS1) y que las condiciones ambientales a lo largo del río Los Patos fuera similar al río Las Pitas.

Otro aspecto relevante en esta discusión es la fuente en el área de la Laguna Cavi, una laguna de altura $(4.500 \mathrm{msm})$. Esta es la fuente más cercana a CS1, pero no demuestra un uso constante (al menos en la muestra de obsidianas analizadas mediante FRX, ya que la determinación macroscópica no es confiable en fragmentos de pequeño tamaño (ver Pintar y Pessarossi-Langlois 2013), por lo que se propone un uso restringido de lagunas de altura como ésta, al menos por parte de grupos cazadoresrecolectores que habitaron CS1.

En suma, el uso de obsidianas durante esta fase de aridez en la región de Antofagasta de la Sierra demuestra un manejo de cinco fuentes a distancias grandes obtenidas durante partidas logísticas, o incluso durante viajes de reconocimiento a grandes distancias (hasta $110 \mathrm{~km}$ ), proponiendo una alta movilidad durante la fase árida del Holoceno Medio (Pintar et al. 2012).

\section{¿Un ecorrefugio o un oasis?}

En la Puna de Atacama se ha propuesto que durante el período comprendido entre 9.000-4.200 cal. a.p. hubo una disminución en las ocupaciones cazadoras-recolectoras y una dispersión hacia hábitats nuevos, como las quebradas de Tulán y Puripica. Sin embargo, no hubo un completo abandono de la región, sino que grupos humanos se desplazaron hacia hábitats con aguadas y sistemas de ríos donde la oferta de recursos se mantuvo estable (Núñez et al. 2013). Estas áreas han sido denominadas refugios ecológicos. El hallazgo de 25 campamentos en una secuencia de $30 \mathrm{~m}$ de depósitos aluviales en la quebrada Puripica llevó a la propuesta que la zona circundante al sitio constituyó un refugio ecológico durante el Holoceno Medio (Grosjean et al. 1997; Núñez et al. 1999). Allí, entre ca. 7.000-4.200 cal. a.p. (6.200-3.800 a.p.) una serie de tormentas de intensidad variada creó un ambiente de recursos de agua, fauna y vegetación concentrados y rodeados de un ambiente hostil. La secuencia de ocupaciones estables y períodos de abandono de CS1, que coincidió con una fase árida en la región de Antofagasta de la Sierra, resultó en la propuesta que el sector intermedio del río Las Pitas consistió un ecorrefugio entre 9.000 y 8.000 cal. a.p. (8.100-7.400 a.p.) (Pintar 2009). A continuación se presenta un análisis crítico de esta propuesta.

La evidencia que apoyó esta propuesta es: (a) que CS1 estuvo deshabitada antes de 9.000 cal a.p. (ca. 8.100 a.p.) y luego fue intensamente ocupada por un milenio (Figura 2), y (b) que Quebrada Seca 3 (a $8 \mathrm{~km}$, en una quebrada de altura) fue intermitentemente ocupada durante ese período. Es posible que la orientación de ambos sitios, la radiación solar y la temperatura hayan jugado un rol decisivo en la selección de sitios para habitar, ya que Quebrada Seca 3 se orienta al $\mathrm{N}$, y está en el sol la mayor parte del día, mientras que CS1 está a la sombra todo el día. Durante este período, el sitio Peñas de la Cruz 1 (en una quebrada aledaña, en el cauce seco del río Ilanco; Figura 1) fue intermitentemente ocupado.

El concepto de ecorrefugio fue originalmente definido en relación a la dispersión de poblaciones cazadoras hacia áreas óptimas y previamente desocupadas (p. ej. quebrada Puripica) como resultado del impacto de las condiciones áridas del Holoceno Medio (Núñez et al. 1999). Estos desplazamientos superan los $40 \mathrm{~km}$ (la distancia aproximada entre Tuina-Puripica). En este sentido, debe resaltarse la diferencia de escala entre la Puna de Atacama y la región de Antofagasta de la Sierra, que es de tamaño mucho menor $\left(2.500 \mathrm{~km}^{2}\right)$. Otra diferencia que debe recalcarse es que si bien CS1 no fue ocupada durante el Holoceno Temprano, en esta región se registran tempranas ocupaciones en sitios próximos, entre 1,5 y $8 \mathrm{~km}$ de CS1 (Figura 1), a saber: Quebrada Seca 3 ca. 11.000 cal. a.p. (ca. 9.800 a.p.; Aschero y Martínez 2001), Punta de la Peña 4 recientemente fechado ca. 10.000 cal. a.p. (9.000 a.p.; Carlos Aschero comunicación personal 2012) y Peñas de la Cruz 1 ca. 9.800 cal. a.p. 
(8.900 a.p.; Jorge Martínez comunicación personal 2013). Por ende, la región de Antofagasta de la Sierra carece de vacíos cronológicos sustanciales entre el Holoceno Temprano y la fase inicial del Holoceno Medio ca. 11.000-7.800 cal. a.p. (ca. 9.800-7.200 a.p.) (Figura 2) debido a la continuidad ocupacional durante este período. A diferencia de los sitios Tuina-4 y San Lorenzo-1 localizados en áreas vulnerables a cambios climáticos (Grosjean et al. 2007), en Antofagasta de la Sierra no hubo una disminución en la densidad de ocupaciones y de vestigios arqueológicos durante el final del Holoceno Temprano y comienzos del Holoceno Medio, apoyando la propuesta que el concepto de Silencio Arqueológico se aplica al área central de la Puna de Atacama, que fue más vulnerable a los cambios climáticos del Holoceno Medio (Núñez et al. 2013).

Además, Antofagasta de la Sierra evidenció un fenómeno a escala diferente que la Puna de Atacama. Los recursos botánicos utilizados en CS1 provinieron del tolar, pajonal y vega, y los animales cazados fueron vicuñas (cuyo hábitat es mayormente el pajonal), y guanacos (cuyo hábitat se infiere fue el tolar). El uso de recursos bióticos asociados a diferentes altitudes sugiere la existencia de un ambiente con recursos heterogéneos en diferentes altitudes a lo largo de los cauces de ríos, sugiriendo que, a diferencia de los refugios ecológicos de Puripica y Tulán en la Puna de Atacama (Grosjean et al 1997; Núñez et al 1999), la cuenca de la Laguna de Antofagasta más bien consistió en una serie de oasis con extensión a lo largo de ríos tributarios rodeados de un ambiente desértico (oasis fluviales, sensu Bruniard 1999), o sea, múltiples áreas en sectores próximos que tuvieron una relativa estabilidad de recursos bióticos, y entre las cuales hubo una cierta sincronicidad durante el Holoceno Medio (p.ej., CS1, Quebrada Seca 3 y Peñas de la Cruz 1). Por lo tanto, esta evidencia da cuenta de la variabilidad ambiental en la Puna salada durante este período de aridez, mostrando la existencia de refugios ecológicos y oasis durante el Holoceno Medio y apoyando las recientes revisiones del modelo de ecorrefugio (Grosjean et al. 2007; Núñez et al. 2013).

Se ha argumentado que durante el Holoceno siempre hubo agua en la región de Antofagasta de la Sierra (Aschero y Hocsman 2011). Es factible que el cerro Galán (5.800 msm), que constituye la vertiente principal del río Las Pitas, haya provisto al río de agua, aunque faltan archivos paleoambientales que lo reflejen. Es posible también que este río haya sido insensible a los cambios climáticos del Holoceno Medio, como fue el río Loa (Grosjean et al. 2005). Como ya fuera observado, el archivo sedimentario de CS1 permite inferir un ambiente estable en el sector intermedio del río Las Pitas ca. 9.000-8.000 cal. a.p. (8.100-7.400 a.p.), sin embargo, los dos hiatos en su ocupación (Figura 2) durante los cuales no existe evidencia de ocupaciones en ningún sector de este río sugieren la alta probabilidad que el río Las Pitas tuviera un curso intermitente durante ese largo período de sequía. Un incremento en la aridez comenzando ca. 7.800-7.200 cal. a.p. (7.200-6.200 a.p.) explicaría un primer período de abandono de este sector del río a favor de áreas más favorables.

Luego de un hiato aproximado de 600 años, ca. 7.200 cal. a.p. (6.200 a.p.), se observan breves ocupaciones en CS1 y QS3 (capa 2(2) en CS1 y capa 2 b8 en QS3) que se caracterizan por tener una baja densidad de restos líticos y óseos. En CS1 las puntas de proyectil tienen características morfológicas diferentes al momento anterior, siendo lanceoladas con base convexa (Figura 5). Es durante este período que se han identificado breves eventos húmedos registrados en Laguna Colorada y el río Mirihuaca (Tchilinguirian y Morales 2013). Es posible que estas ocupaciones en el sector medio del río Las Pitas-Quebrada Seca conformen más una situación ambiental de ecorrefugio restringido espacialmente que a condiciones de oasis antes presentes y que las condiciones húmedas habrían permitido la recuperación de recursos bióticos y la concentración de grupos cazadores-recolectores por algún tiempo.

Sin embargo, y a diferencia del refugio ecológico en la Quebrada de Puripica, estas ocupaciones no persistieron, ya que fueron seguidas por un segundo período de abandono de CS1 por aproximadamente 2.000 años, entre ca. 7.000-5.000 cal. a.p. (ca. 6.000-4.500 a.p.), y de QS3 por 800 años, entre ca. 7.000-6.200 cal. a.p. (6.200-5.400 a.p.). Es factible que durante esta segunda fase del Holoceno Medio los grupos de cazadores-recolectores hayan adoptado estrategias de movilidad y asentamiento diferentes, y que frente a condiciones de mayor aridez hayan ocupado quebradas de altura sobre los $4.100 \mathrm{msm}$ donde hay manantiales que se alimentan de aguas subterráneas. 


\section{Conclusiones}

Por lo tanto, durante el Holoceno Medio en la región de Antofagasta de la Sierra se dieron condiciones ambientales particulares que favorecieron una continuidad en las ocupaciones de cazadoresrecolectores y una interrupción de ellas a causa del incremento en la aridez y el estrés ambiental. A diferencia de la Puna de Atacama, las condiciones de aridez en Antofagasta de la Sierra no fueron tan severas durante el inicio del Holoceno Medio, permitiendo la formación de varios oasis fluviales que favorecieron la subsistencia de grupos de cazadoresrecolectores. Cueva Salamanca 1 proporcionó un espacio conveniente para la realización de múltiples actividades realizadas por un grupo residencial. A pesar de la aridez generalizada en la Puna durante el Holoceno Medio, la estabilidad de recursos a lo largo del río Las Pitas permitió la planificación de ocupaciones reiteradas en Cueva Salamanca 1 en la primavera-verano (y posiblemente otoño) durante el milenio comprendido entre 9.000 y 8.000 cal. a.p. (8.100-7.400 a.p.). Paralelamente, hubo ocupaciones intermitentes en Quebrada Seca 3 y Peñas de la Cruz 1 (posiblemente utilizados como sitios de caza) hasta ca. $7.800 \mathrm{cal}$ a.p. (7.200 a.p.) (Figura 2).

Luego de este período se registraron dos hiatos de ocupación entre ca. 7.800 -7.200 cal. a.p. (7.200-6.200 a.p.) y 7.000-6.300/5.000 cal. a.p. (ca. 6.000-5.400/4.500 a.p.), interrumpidos por un breve período de reocupación ca. 7.200-7.100 cal. a.p. (6.200-6.100 a.p.) que coincidió con condiciones de mayor humedad, y durante el cual pudo haberse formado un ecorrefugio en el curso medio del río Las Pitas y Quebrada Seca. Durante estos hiatos las condiciones de aridez se incrementaron y los oasis se retrajeron, sugiriendo un uso limitado del ambiente y restringido a zonas menos vulnerables al estrés ambiental y a quebradas de altura con aguadas por sobre los $4.100 \mathrm{msm}$.

Finalmente, y al final del Holoceno Medio, CS1 es reocupada ca. 5.000 cal. a.p. (4.500 a.p.), así como el sitio Punta de la Peña 4 (a 2 km de CS1), que cuenta con un fechado de ca. 5.100 cal. a.p. (4.600 a.p.) (Hocsman 2006). Estas ocupaciones muestran una reorganización del uso del ambiente (que se inició durante el período de aridez generalizada) que involucró el uso de varias zonas en el curso medio del río Las Pitas, donde se encuentran los sitios de Punta de la Peña y Peñas Chicas (Aschero y Hocsman 2011) y el sitio QS3 en una quebrada de altura. Dichas ocupaciones coinciden con el inicio de una fase más húmeda en el río Las Pitas (Tchilinguirian 2009). Las últimas ocupaciones que se registran en Cueva Salamanca 1 ocurren ca. 3.700 cal. a.p. (3.500 a.p.). Las semillas y tallos de quinua indican que los habitantes de esta cueva manejaban una economía que incluía recursos domesticados y que este período conforma a la transición hacia economías productivas con camélidos domesticados y cultígenos (Aschero y Hocsman 2011).

Agradecimientos: A todos los integrantes de las campañas a Cueva Salamanca a lo largo de todos estos años. A mis colegas, estudiantes y familia quienes han colaborado en múltiples formas. A Mary Beth Booth por la confección de la Figura 1, y a Kelly Ramsey por la toma de fotos. A los evaluadores del trabajo por sus muy valiosos comentarios. Los trabajos de campo en Cueva Salamanca 1 fueron realizados con los subsidios National Science Foundation (SBR-9321263); Earthwatch, The Center for Field Research; PICTCONICET 09888; UBACyT F445; PIP-CONICET 11220100100208; el apoyo logístico de la Empresa Siner, S.A. y una beca J. William Fulbright por la que suscribe.

\section{Referencias Citadas}

Abbott, M., G. Seltzer, K. Kelts y J. Southon 1997. Holocene paleohydrology of the Tropical Andes from lake records. Quaternary Research 47:70-80.

Adovasio, J.M. 1977. Basketry Technology. A Guide to Identification and Analysis. Aldine Manuals on Archeology, Chicago.

Aschero, C. 1988. Arqueología precerámica de Antofagasta de la Sierra. Quebrada Seca: una localidad de asentamiento. Informe de Investigador. CONICET, Buenos Aires. Manuscrito en posesión del autor.
Aschero C. y S. Hocsman 2011. Arqueología de las ocupaciones cazadoras-recolectoras de fines del Holoceno Medio de Antofagasta de la Sierra (Puna meridional argentina). Chungara Revista de Antropología Chilena 43:393-411.

Aschero, C. y J. Martínez 2001. Técnicas de caza en Antofagasta de la Sierra, puna meridional Argentina. Relaciones de la Sociedad Argentina de Antropología 26:215-241.

Babot, M.P. 2011. Cazadores-recolectores de los Andes centrosur y procesamiento vegetal. Una discusión desde la Puna 
meridional argentina (ca. 7.000-3.200 años a.p.). Chungara Revista de Antropología Chilena 43:413-432.

Baied, C. y J. Wheeler 1993. Evolution of high Andean Puna ecosystems: environment, climate, and culture change over the last 12,000 years in the Central Andes. Mountain Rresearch and Development 13:145-156.

Barrett, A. y E. Gifford 1933. Miwok Material Culture: Indian life of the Yosemite Region. Yosemite Association, El Portal.

Bruniard, E.D. 1999. El escenario geográfico. En Nueva Historia de la Nación Argentina, Tomo La Argentina Aborigen. Conquista y Colonización, pp. 39-63. Academia Nacional de la Historia, Planeta, Buenos Aires.

Cabrera, A. 1957. La vegetación de la Puna argentina. Revista de Investigaciones Agrícolas 9(4):317-412.

Davidson, D. 1928. The family hunting territory in Australia. American Anthropologist 30:614-631.

García Salemi, M. A. 1986. Geomorfología de regiones secas: Antofagasta de la Sierra, Provincia de Catamarca. Centro de Estudios Regiones Secas 4:5-13.

Grosjean, M. 2001. Mid-Holocene climate in the south-central Andes: humid or dry? Science 292:2391-2392.

Grosjean, M. y L. Núñez 1994. Cambios ambientales pleistocenoholocénicos: ocupación humana y uso de recursos en la Puna de Atacama (Norte de Chile). Estudios Atacameños 11:11-24.

Grosjean, M., L. Núñez e I. Cartajena 2005. Cultural response to climate change in the Atacama desert. En $23^{\circ}$ S: The Archaeology and Environmental History of the Southern Deserts, editado por M. Smith y P. Hesse, pp. 156-171. National Museum of Australia, Canberra.

Grosjean, M., L. Núñez, I. Cartajena y B. Messerli 1997. MidHolocene climate and culture change in the Atacama Desert, Northern Chile. Quaternary Research 48:239-246.

Grosjean, M., C. Santoro, L. Thompson, L. Núñez y V. Standen 2007. Mid-Holocene climate and culture change in the South Central Andes. En Climate Change and Cultural Dynamics: a Global Perspective on Mid-Holocene Transitions, editado por D. Anderson, K. Maasch y D. Sandweiss, pp. 51-115. Academic Press, San Diego.

Hocsman, S. 2006. Producción Lítica, Variabilidad y Cambio en Antofagasta de la Sierra - ca. 5500 - 1500 AP. Tesis para optar al grado de Doctor en Ciencias Naturales, Facultad de Ciencias Naturales y Museo, Universidad de La Plata, La Plata.

Lee, R. 1976. !Kung spatial organization: an ecological and historial perspective. En Kalahari Hunter-Gatherers. Studies of the !Kung San and their Neighbors, editado por R.B. Lee e I. DeVore, pp. 74-97. Harvard University Press, Cambridge.

Markgraf, V. 1985. Paleoenvironmental history of the last 10,000 years in northwestern Argentina. Zentralblatt fur Geologie und Palaontologie 11/12:1739-1749.

Marozzi, A. 2012. Tafonomía de Vertebrados Holocénicos del Sitio Arqueológico Cueva Salamanca 1 en la Puna Salada Argentina. Tesina de grado. Facultad de Ciencias Exactas, Físicas y Naturales. Universidad Nacional de Córdoba, Córdoba.

Martínez, J. 2005. Tecnología de cazadores en la puna meridional argentina: el caso de Peñas de la Cruz 1. Mundo de Antes 4:25-49.
2012. Evidence of early human burials in the Southern Argentinian Puna. En Southbound. Late Pleistocene Peopling of Latin America, editado por L. Miotti, M. Salemme, N. Flegenheimer y T. Goebel, pp. 75-78. Center for the Study of the First Americans, Texas.

Mondini, M., J. Martínez, E. Pintar y M. C. Reigadas 2013. Middle Holocene foraging, mobility and landscape use in the Southern Argentinean Puna: hunter-gatherers from Antofagasta de la Sierra, Catamarca, Argentina. Quaternary International 307:66-73.

Mondini, M., H. Panarello y A. Zangrando 2010. First isotopic evidence in southern Puna camelids throughout the Holocene. Póster presentado en el $11^{\text {th }}$ Conference of International Council for Archaeozoology, Paris.

Núñez, L., I. Cartajena y M. Grosjean 2013. Archaeological silence and ecorefuges: Arid events in the Puna of Atacama during the Middle Holocene. Quaternary International 307:5-13.

Núñez, L., M. Grosjean e I. Cartajena 1999. Un ecorefugio oportunístico en la puna de Atacama durante eventos áridos del Holoceno Medio. Estudios Atacameños 17:125-174.

Núñez, L.A. y C. Santoro 1988. Cazadores de la puna seca y salada del área centro-sur andina (Norte de Chile). Estudios Atacameños 9:11-60.

Olivera, D., P. Tchilinguirian y M.J. De Aguirre 2004. Paleoambiente y arqueología en la puna meridional argentina. Relaciones de la Sociedad Argentina de Antropología 29:229-247.

- - - - 2006. Cultural and environmental evolution in the meridional sector of the Puna of Atacama during the Holocene. Change in the Andes: Origins of Social Complexity, Pastoralism and Agriculture. Actas XIV Union Internacionale des Sciences Préhistoriques et Protohistoriques, pp. 1-7. University de Liege, Bélgica.

Pintar, E. 2004. Cueva Salamanca 1. Ocupaciones altitermales en la puna sur. Relaciones de la Sociedad Argentina de Antropología 29:356-366.

- - - - 2008a. Estrategias de caza y recolección: una aproximación a la división sexual del trabajo en la puna salada. Relaciones de la Sociedad Argentina de Antropología 33:133-154.

- - - 2008b. Astiles, intermediarios y sistemas de armas en la puna salada. Cazadores- Recolectores del Cono Sur, Revista de Arqueología 3:115-128.

- - - 2008c. High altitude deserts: hunter-gatherers from the salt puna, northwest Argentina. International Journal of South American Archaeology 2:47-55.

- - - 2009. Un "ecorrefugio" en la cuenca de la Laguna de Antofagasta (Puna Salada) hacia 7900 y 6200 años AP. Revista Arqueología 15:85-108.

- - - 2013. Desert hunter-gatherers: mobility and aridity thresholds. A view from the Argentine Salt Puna. En Hunter-Gatherers from a High Elevation Desert. People of the Salt Puna, editado por E. Pintar. Archaeopress, British Archaeological Reports, Oxford, en revisión.

Pintar, E., J. Martínez y M. Glascock 2011. Obsidian sourcing and mobility strategies in a high elevation desert in NW Argentina. Ponencia presentada en "Applications of XRF and LA-ICP-MS". $76^{\text {th }}$ Annual Meetings of the Society for American Archaeology. Sacramento, California. 
Pintar, E., J. Martínez y M. Glascock 2012. Obsidian acquisition strategies in a high elevation desert in NW Argentina. Póster presentado en 77th Annual Meetings of the Society for American Archaeology, Memphis, Tennessee.

Pintar, E. y J. Pessarossi-Langlois 2013. pXRF Sourcing of obsidian artifacts from Salamanca Cave, Argentina. International Association of Obsidian Studies Bulletin 48:10-14.

Reigadas, M.C. 2012. Cueros de Cueva Salamanca 1 (Antofagasta de la Sierra, Catamarca): una vía de identificación taxonómica y algo más. II Encuentro Latinoamericano de Zooarqueología, Santiago de Chile.

Reigadas, M.C. y M. Mondini 2010. Holocene hunter-gatherers in the Puna. Integrating zooarchaeological evidence in Antofagasta de la Sierra (Argentina). Ponencia presentada en el $11^{\text {th }}$ Conference of International Council for Archaeozoology, Paris.

Rodríguez, M.F. 1999. Arqueobotánica de Quebrada Seca 3 (puna meridional argentina): especies vegetales utilizadas en la confección de artefactos durante el Arcaico. Relaciones de la Sociedad Argentina de Antropología 14:159-185.

Rodríguez, M.F. y E.L. Pintar. 2013. Especies vegetales y tecnofacturas en la Puna salada. Cueva Salamanca 1. Ponencia presentada en XXXIV Jornadas Argentinas de Botánica, La Plata, provincia de Buenos Aires.

Rodríguez, M.F., Z. Rúgolo de Agrasar y C. Aschero 2003. El género Deyeuxia (Poaceae, Agrostideae) en sitios arqueológicos de la Puna meridional argentina, provincia de Catamarca. Chungara Revista de Antropología Chilena 35:51-72.

Santoro, C. y L. Núñez 1987. Hunters of the dry puna and the salt puna in northern Chile. Andean Past 1:57-109.

Speth, J. 2010. Boiling vs. roasting in the Paleolithic: broadening the "Broadening Food Spectrum". Journal of the Israel Prehistoric Society 40:63-83.
Tchilinguirian, P. 2009. Paleoambientes Holocenos en la Puna Austral (27 S): Implicancias Geoarqueológicas, Argentina. Tesis para optar al grado de Doctor, Universidad de Buenos Aires, Argentina.

Tchilinguirian, P. y M. Morales 2013. Mid-Holocene paleoenvironments in Northwestern Argentina: Main patterns and discrepancies. Quaternary International 307:14-23.

Tchilinguirian, P., D. Olivera y L. Grana 2007. Paleoambientes sedimentarios y su aplicación en arqueología. Antofagasta de la Sierra, Catamarca. En Metodologías Científicas Aplicadas al Estudio de Bienes Culturales, editado por A. Pifferetti y R. Bolmaro, pp. 472-482. Primer Congreso Argentino de Arqueometría, Rosario.

Thoms, A. 2009. Rocks of ages: propagation of hot-rock cookery in western North America. Journal of Archaeological Science 36:573-591.

Valero-Garcés, B., A. Delgado-Huertas, N. Ratto, A. Navas y L. Edwards 2000. Paleohydrology of Andean saline lakes from sedimentological and isotopic records, Northwestern Argentina. Journal of Paleolimnology 24:343-359.

Valero-Garcés, B., M. Grosjean, A. Schwalb, M. Geyh, B. Messerli y K. Kelts 1996. Limnogeology of Laguna Miscanti: Evidence for mid to late Holocene moisture changes in the Atacama Altiplano (Northern Chile). Journal of Paleolimnology 16:1-21.

Yacobaccio, H. y M. Morales 2005. Mid-Holocene environment and human occupation of the Puna (Susques, Argentina). Quaternary International 132:5-14.

Young, J. y W. Franklin 2004. Territorial Fidelity of Male Guanacos in the Patagonia of Southern Chile. Journal of Mammalogy 85:72-78. 
